\title{
Definition of a fault permeability predictor from outcrop studies of a faulted turbidite sequence, Taranaki, New Zealand.
}

C. Childs ${ }^{1}$, J.J. Walsh ${ }^{1}$, T. Manzocchi ${ }^{1}$, J. Strand ${ }^{1}$, A. Nicol ${ }^{2}$, M. Tomasso ${ }^{3,4}$, M.P.J. Schöpfer ${ }^{1}$ \& A. C. Aplin ${ }^{5}$

${ }^{1}$ Fault Analysis Group, School of Geological Sciences, University College Dublin, Belfield, Dublin 4, Ireland. (Email: conrad@fag.ucd.ie).

${ }^{2}$ Institute of Geological and Nuclear Sciences, PO Box 30368, Lower Hutt, New Zealand.

${ }^{3}$ Marine and Petroleum Geology Group, School of Geological Sciences, University College Dublin, Belfield, Dublin 4, Ireland.

${ }^{4}$ Present Address: Bureau of Economic Geology, The University of Texas at Austin, University Station, Box X, Austin, Texas 78713-8924, U.S.A.

${ }^{5}$ School of Civil Engineering and Geosciences, School Office: Cassie Building,University of Newcastle upon Tyne, NE1 7RU, UK

Corresponding author: C. Childs

Words: 9114 (including: abstract - 200: acknowledgements - 96)

References: 26

Tables: 0

Figures: 17

Abbreviated title: Fault permeability predictor Taranaki Basin

\begin{abstract}
Post-depositional normal faults within the turbidite sequence of the Late Miocene Mount Messenger Formation of the Taranaki basin, New Zealand are characterised by granulation and cataclasis of sands and by the smearing of clay beds. Clay smears maintain continuity for high ratios of fault throw to clay source bed thickness (c. 8), but are highly variable in thickness, and gaps occur at any point between the clay source bed cutoffs at higher ratios. Although cataclastic fault rock permeabilities may be significantly lower (c. 2 orders of magnitude) than host rock sandstone permeabilities, the occurrence of continuous clay smears, combined with low clay permeabilities (10's to 100 's $\mathrm{nD}$ ) means that the primary control on fault rock permeability is clay smear continuity. A new permeability predictor, the Probabilistic Shale Smear Factor (PSSF), is developed which incorporates the main characteristics of clay smearing from the Taranaki Basin. The PSSF method calculates fault permeabilities from a simple model of multiple clay smears within fault zones, predicting a more heterogeneous and realistic fault rock structure than other approaches (e.g. Shale Gouge Ratio, SGR). Nevertheless, its averaging effects at higher ratios of fault throw to bed thickness provide a rationale for the application of other fault rock mixing models, e.g. SGR, at appropriate scales.
\end{abstract}


A large number of parameters are required to define a model of a fault system for the purposes of examining the flow response of a faulted siliciclastic reservoir. These parameters can be divided into those which define the geometrical scaling properties of the fault system and those which define the flow properties of the faults. Fault properties are generally included in reservoir simulators as transmissibility multipliers which modify the flow from one side of a fault to the other (Manzocchi et al. 1999). The calculation of geologically meaningful fault transmissibility multipliers requires predictors of both fault rock thickness and permeability. Fault rock thickness, and its variability, can usually be predicted from the well established positive correlation with fault displacement. Definition of a fault rock permeability predictor is a much more difficult task due to the strongly heterogeneous and anisotropic nature of fault rocks. Permeability predictors are necessarily based on highly simplified and idealised conceptual models of fault rock which, it is hoped, capture the main controls. Conventional fault permeability predictors vary from those which implicitly assume that fault rocks represent a mixed aggregate of the faulted sequence, with equivalent average permeabilities, such as the Shale Gouge Ratio method (Yielding et al. 1997, Manzocchi et al. 1999; Harris et al. 2002; Sperrevik et al. 2002), to those which provide a simple means of modeling clay smears within fault zones, such as the Shale Smear Factor method (Lindsey et al. 1993). These methods are generally informed by previously published observational and quantitative constraints derived from outcrop studies and by fault permeability measurements from outcrop and sub-surface datasets. A shortcoming of previous work is, however, that there have been relatively few detailed studies of fault rock distribution within heterolithic sequences, and these studies rarely consider the full range of issues associated with fault property calculation, from descriptive aspects through to predictive methods. In this paper we present a detailed description of the fault rock distributions associated with normal faults offsetting a poorly lithified, sand/clay turbidite sequence from the Taranaki Basin, North Island, New Zealand. Quantitative constraints from outcrop studies combined with fault rock permeability measurements then provide a basis for the development of a novel permeability predictor for faults, referred to as the Probababilistic Shale Smear Factor method. This predictor is compared with existing methods, such as the Shale Gouge method, and recommendations are made for their application in reservoir modelling. Although the Probababilistic Shale Smear Factor method is developed here for faults offsetting poorly lithified turbidites, its application is not necessarily limited to this setting and it may be applicable to any settings where continuous clay smears are developed.

\section{Geological setting of study area}

The study area is on the eastern margin of the Taranaki Basin, on the west coast of North Island, New Zealand (Fig. 1). The Taranaki Basin is New Zealand's only hydrocarbon producing basin and the study area was chosen primarily for its excellent coastal exposures of faulted deep-water turbidites of the upper Miocene Mount Messenger Formation, which is one of the main hydrocarbon reservoir intervals in the Taranaki Basin (Fig. 2). Oil and gas fields producing from the Mount Messenger Fm lie c. $40 \mathrm{~km}$ to the SW of the outcrop study area (Fig. 1). Here we provide a 
brief outline of the geological setting of the study area and descriptions of the outcrop dataset which is the basis for this study.

The Taranaki Basin contains upper Cretaceous and Tertiary strata with a maximum combined thickness of $9 \mathrm{~km}$ (King \& Thrasher 1996). The basin originated in the late Cretaceous as a result of extension related to opening of the Tasman Sea and break-up of East Gondwana and since then has had a complex post-Cretaceous development, with several subsidence events related to relative movements of the Australian and Pacific plates (King \& Thrasher 1992, 1996). Crustal extension in the last $6 \mathrm{Ma}$ is believed to arise from back-arc rifting in response to roll-back of the subducting Pacific Plate beneath the North Island. In the northern Taranaki Basin, $1 \mathrm{~km}-1.5 \mathrm{~km}$ of post-Miocene extension has taken place across a NNE-trending rift (variously referred to as the Turi Fault Zone or the Northern Graben) which is up to about $100 \mathrm{~km}$ wide (Fig. 1; Nicol et al. 2005). The upper Miocene Mount Messenger Fm turbidites examined in this study are located within the rift, close to its eastern margin (Figs 1,2), and are displaced by post-depositional normal faults formed during the most recent phase of crustal extension. The Mount Messenger Fm is continuously exposed for approximately $20 \mathrm{~km}$ along a coastal cliff section from Mokau in the north to Pukearuhe in the south (Figs 1, 2). This coastal section trends NNE-SSW and is up to $200 \mathrm{~m}$ high at the White Cliffs. The regional stratigraphic dip is low, averaging $2^{\circ}-5^{\circ}$ to the SW. Along the exposure the Mount Messenger has a measured stratigraphic thickness of about $850 \mathrm{~m}$ and ranges in age from about $9 \mathrm{Ma}-12 \mathrm{Ma}$ (King et al. 1993; King \& Thrasher 1996). The rate of coastal erosion is very high (c. $1 \mathrm{~m}$ per year, R. Gibbs pers. comm. 2003) so that the outcrop is relatively fresh and large faults (with tens of metres offset) are well exposed.

The Mount Messenger Formation represents a westerly prograding, line-sourced turbidite system, so the NNE-SSW outcrop transect passes up through the sequence from basin-floor to slope. The outcrops record a north-south, fining- and shallowing-upwards, transect from basin-floor fan, through inner fan, to base-of-slope and lower-slope depositional environments. The sediments themselves comprise interbedded sandstones, siltstones and mudstones, with frequent thin volcaniclastic beds. Initial basin-floor fan deposition is recorded in the exposures around Tongaporutu River (Fig. 2). In both the coastal section and inland exposures, a series of stacked sand-rich fan units are observed. In detail, the mid-fan sediments comprise tabular, massive to thickly bedded sandstones with frequent internal scouring and sand-bed amalgamation. These pass both upwards and laterally into fan-fringe environments characterised by more thinly-bedded sandstones with mudstone interbeds, with sand bodies becoming progressively more isolated within mudstones (e.g. Browne et al. 1996). The inter-fan sediments are represented by bedded to slumped mudstones, with occasional thin sandstone or siltstone beds. Inner-fan canyon-fill sediments are observed in the Waikiekie section (about $3 \mathrm{~km}$ south of Tongaporutu, Fig.2). The lower fill comprises nested, offset-stacked incising channels. Each channel fill typically comprises a basal mudstone-clast lag, overlain by massively bedded sandstone. Moving up through the fill of the canyon, the channels become more isolated, with finer fills, and associated thinly-bedded levee and overbank deposits are present. Base-of-slope sedimentation is recorded at Pukearuhe (Fig. 2) 
and the southern section of the White Cliffs ( $<1 \mathrm{~km}$ north of Pukearuhe, Fig. 2). This comprises thinly bedded, bioturbated sandstones and mudstones, attributed to channel-fill, proximal levee and distal levee sedimentation (Browne \& Slatt,2002). The distal levee sediments have sub-parallel bedding, which can be correlated over large distances, whereas the bedding frequently changes dip in the proximal levee deposits. The channel scours are of varying size, with the largest in outcrop viewed just south of the Pukearuhe Beach entrance.

Faults within the Mount Messenger Fm are post-depositional normal faults which outcrop along the entire coastal section and locally inland, most notably the Mokau road section (Fig. 2). The faults have throws (i.e. vertical displacements) of up to $60 \mathrm{~m}$, and fault throws as low as $1 \mathrm{~mm}$ can be routinely identified and measured. There are two dominant fault sets striking 005 and 045 , each comprising two fault dip directions to define a quadrimodal population of fault orientations (similar to that described by Reches \& Dieterich 1983), with the majority of the large faults (throw $>10 \mathrm{~m}$ ) part of the 045 set. Because fault strikes are at a low angle to the general trend of the outcrop, serial sections through individual faults are commonplace. There are very few fault kinematic indicators but those observed indicate dip-slip normal movement. The faults are thought to have formed when the sediments were at or close to their maximum burial depth of $1 \mathrm{~km}-2 \mathrm{~km}$, and there is no evidence in the study area of faulting during deposition of the Mount Messenger Fm.

\section{Structural characterisation}

Structural characterisation of the Taranaki study area was directed towards establishing the quantitative characteristics of fault systems that are important in the parameterisation of faulted reservoir models. Since there are few, if any, quantitative constraints on faults within turbidite sequences, our study examined all of the potentially significant factors including the geometrical properties of the fault system, the internal structure of fault zones and the permeabilities of fault rocks. The fault system was characterised primarily from outcrop studies complemented by analyses of a 3D seismic reflection survey of the Ngatoro and Kaimiro oil and gas fields (Fig. 1). This paper concentrates on one technical aspect: the analysis and modeling of fault rock content and its implications for the definition of fault property algorithms used in reservoir modeling. Quantitative constraints on fault rock content and flow properties were derived from the analysis of fault zones in both $2 \mathrm{D}$ (i.e. individual cross-sections) and 3D (i.e. multiple cross-sections) and provide a basis for parameterising fault-related properties, such as fault rock thickness and permeability, in reservoir models. 
The predominant fault rock types formed in Taranaki are shear bands, i.e. narrow zones of high shear strain. The composition and width of these shear bands varies greatly between different lithologies, defining a spectrum of structures from very narrow $(<<1 \mathrm{~mm})$ clay rich zones developed in fine grained silt and mudstones (Fig. 3a) to deformation bands in porous sandstones which may have widths several times larger than their displacement (Fig 3b, 4e). Since these shear bands are the primary components of both large and small faults, when large faults (displacements of tens of metres) are examined in detail the bulk of the fault rock volume is generally found to be mainly comprised of anastomosing swarms of shear bands (e.g. Figs 3d, 4b, 4c). Fault rock content is strongly heterogeneous reflecting the variations in host rock sequences that are incorporated into the faults (Figs $4 b, c, f)$. The main slip surfaces of large faults often consist of relatively thick (> 1 $\mathrm{cm}$ ), continuous, zones of clay rich fault rock, either as malleable clay gouge (Fig. $4 \mathrm{~g}$ ) or as amalgamations of relatively harder dark clay layers (Fig. 4b, c); as is discussed in more detail below, these clay layers are formed by smearing of clay rich source beds along faults.

Fault rock mineralogies are the same as those of the host rocks, comprising predominantly quartz, albite, muscovite, biotite and chlorite, with occasional calcite, montmorillonite and zeolite; a mineral assemblage typical of sediments derived from erosion of a low grade metamorphic source area. Montmorillonite, occasionally encountered in clay fault rocks, is probably derived from tuff source layers. Shear bands within the coarser, i.e. sand, lithologies, (Fig. 5) show a general grain size reduction particularly of the weaker mineralogical components, i.e. feldspars, micas and lithic fragments (see Fig. 5), together with a reduction in the proportion of feldspar and an increase in mica relative to host rock (possibly arising from the breakdown of albite to mica). Similar changes are most likely a feature of clay derived fault rock, though the extent of grain size comminution is very difficult to quantify. Apart from circumstances in which malleable clay fault rocks are generated, and clearly represent clay gouges, we hereafter use the more general term of clay smear, whatever its origin, for entirely clay derived fault rock.

In general breccias are not developed in the faults at Taranaki, reflecting the poor lithification of the sequence at the time of faulting. The only exceptions to this rule are thin (typically $<10 \mathrm{~cm}$ ) quartz cemented siltstone breccia sheets found on some of the largest faults in the area, e.g. at Omahu $\mathrm{Pa}$ (Fig. 4d) and Mangapukatea. The presence of these anomalous cemented breccias in otherwise poorly lithified sediments suggests localised flow of deep-sourced brines along larger faults during fault movement.

\section{Fault rock thickness}

Fault rock thickness was measured as the total thickness encountered on a perpendicular traverse across a fault zone. Measurement of the thickness of fault breccias can often be highly subjective due to the often arbitrary and scale-dependent distinction between breccia clasts and undeformed 
rock; this is not a problem at Taranaki where breccias are rare and so, as a consequence, fault rock measurements are far more objective than in most settings.

Fault rock thickness relationships at Taranaki differ between facies over the measured scale range of fault throw (Fig. 6). At low throws, fault rock thicknesses are higher in the coarser grained facies than in the finer grained facies. The massive sandstone facies in particular have large fault rock thicknesses at low throws due to the development of wide deformation bands. At higher throw values the data for the different facies converge (on a log-log plot) so that they are similar at throws $>50 \mathrm{~cm}$.

A general positive correlation between fault throw and average fault rock thickness has been reported by a number of authors (Robertson 1983; Hull 1988; Marrett \& Allmendinger 1990)). In the Taranaki dataset it has a power-law slope of $c .1$ and is most clearly seen when the massive sandstones are excluded. The data define a two order of magnitude scatter in average thickness at a given throw value, and are generally consistent with previously published material for normal faults in siliciclastic sequences. The maximum and minimum observed thicknesses vary over three orders of magnitude with as much as 2.5 orders of magnitude variation observed for individual fault traces (Fig. 6). The scatter in these data, on a log-log plot, decreases with increasing throw, a feature which is partly attributed to a decrease in the proportion of fault trace length that is measurable along larger faults.

\section{Shale smearing}

Outcrops where clay layers are interbedded with sandstones and are offset by faults with throws less than the sandstone thickness, indicate that clay smears are a crucial component of faults in the study area (Figs $3 c, 7 a$ ); in these circumstances single smears can be linked to their source layer. Such outcrops at Tongaporutu and Mokau have been used to quantify the continuity of clay smears along fault traces between the footwall and hangingwall cutoffs of clay source layers. Measurements of shale smear factor (SSF, the ratio between fault displacement and apparent source bed thickness i.e. as measured along the fault trace; Lindsay et al. 1993) and clay smear thickness (Fig. 8) demonstrate a decrease in the minimum clay smear thickness with increasing shale smear factor and show that clay smears are generally continuous when the fault displacement is less than $c .8$ times the apparent source layer thickness.

Faults which comprise individual smears derived from single source layers represent a small, though special, subset of the faults studied (e.g. Figs 3c, 7a). In practice, most faults comprise multiple smears arising from different source layers which are offset by multiple slip surfaces (e.g. Fig. 7b). These complexities are compounded by the fact that the thicknesses of even individual smears do not vary in a regular manner along their length. Individual clay smears frequently ( $c$. $50 \%$ of those inspected) taper from the clay source bed on one (e.g. Fig. $7 \mathrm{a}$ ), or very rarely both, 
sides of the fault. However the point of minimum clay smear thickness (or gap in the smear) may occur at any point along the smear. On scales larger than an individual smear, clay smear thicknesses are highly irregular (Figs 3c, 7b, 8b) and the locations of smear breaching are controlled by strain distributions, and slip surfaces, within the fault zone. Shear strains are generally highest at the margins of fault zones so that clay smears are likely to become breached at these locations. Given the numerous slip surfaces and internal complexities of individual fault zones, large numbers of clay smears on metre-decametre scale faults often amalgamate to form highly continuous clay layers (Fig. 7c).

In addition to clay smearing, in which clay extends somewhere between the footwall and hangingwall location of a given source layer, there are also examples of clay rich fault rock occurring on parts of faults which have not been bypassed by a clay source layer. The generation mechanism for these clay enriched zones, which is likely to include a contribution from clay injection, is the subject of ongoing work.

\section{Fault rock permeabilities}

The rocks within the Mount Messenger Fm in Taranaki are very weakly cemented and therefore difficult to core for permeability measurement. Bench mounted cores of hand samples of undeformed sediments provided some samples for Hassler sleeve measurement, but not for fault rocks. The majority of permeability measurements were made using a bench mounted minipermeameter applied to flat surfaces of hand samples. The lower limit of measurement for both the Hassler sleeve and mini-permeameter is estimated to be c. $0.01 \mathrm{mD}$, although measurements lower than c. $0.1 \mathrm{mD}$ should in practice be regarded as maximum values. Lower permeabilities, derived from siltstones and mudstones and their fault rock equivalents, were calculated from mercury injection curves using a mudstone pore space model developed by Yang \& Aplin (1998). Comparison between results obtained using this method and those obtained from standard techniques show that this method is accurate to within a factor of three of the true value (Yang \& Aplin in press).

Permeability measurements are for fault and host rocks from a range of the facies types encountered within the Mount Messenger Fm. The measured permeabilities lie within the range 6 $\mathrm{nD}-1500 \mathrm{mD}$ and show a general correlation with grain size (Fig. 9a). The range of permeabilities of the unfaulted sediments within each facies covers up to seven orders of magnitude (for thick bedded sandstone facies), reflecting the lithological heterogeneity within each facies. The measured fault rock permeabilities cover a slightly more limited range, towards the lower end of those of corresponding host rocks. Where it is possible to measure the permeability of a host rock and its direct faulted equivalent, the maximum permeability reduction was found to be two orders of magnitude (Fig. 9a). This reduction due to fault processes, i.e. cataclasis, porosity collapse etc., is negligible when compared with the difference in permeability between different lithologies, i.e. 
sands and clays, within a single facies. The permeability data therefore suggest that the most efficient means of decreasing fault zone permeability is the smearing and incorporation of low permeability lithologies (i.e. clays and siltstones) into fault zones. This conclusion favours the application of shale smear algorithms in fault property modeling (Lindsay et al. 1993; Fulljames et al. 1997; Yielding et al. 1997), a suggestion that will be returned to later in this paper.

The phyllosilicate fraction within selected fault and host rocks was measured from SEM and thin section point counting. Although there are significant uncertainties in determining phyllosilicate content (due largely to the fine grained and poorly lithified nature of the rocks) the data demonstrate a decrease in permeability with increasing phyllosilicate content. Fault rock permeabilities decrease by $c .6$ orders of magnitude over the range of phyllosilicate content from deformation bands in relatively clean sandstones to clay gouges or smears. Similar negative correlations between phyllosilicate content and permeability have been used to underpin the Shale Gouge Ratio method for attaching properties to faults in flow simulators (Manzocchi et al. 1999). This very significant aspect will be returned to in our consideration of fault parameters for modeling.

\section{Summary - structural characterisation}

The purpose of the outcrop study was to characterise the fault rock content of fault zones within the turbidite sequence of the Taranaki Basin. Several quantitative aspects have been defined which provide important constraints for the definition of models or algorithms for fault property modeling. Correlations between fault rock thickness and displacement provide a means of predicting fault rock thickness. Faulting causes a reduction in grain size due to preferential comminution of weaker minerals (feldspars, micas and lithic fragments rather than quartz), causing a maximum observed permeability reduction of two orders of magnitude. Clay smears are a common feature of these fault zones, with smears which are generally continuous when the fault throw is less than eight times the clay source rock thickness. The difference in permeability between the different lithologies within a sequence is several orders of magnitude larger than the difference in permeability between a fault rock and its parent host rock. The effect of smearing of low permeability rocks, such as clays (which have permeabilities in the nanoDarcy to 100 nanoDarcy range), along a fault therefore has a much greater impact on fault permeability than other fault-related processes (i.e. cataclasis, porosity collapse, etc.). This and other observational data provide support for the application of certain shale smear algorithms, such as shale smear factor (Lindsay et al. 1993), in fault property modeling. There is, nevertheless, a negative correlation between the proportion of phyllosilicates in a fault rock and its permeability, a feature which provides some support for the use of the shale gouge ratio algorithm in fault property modeling (Yielding et al. 1997). In the next section, we explore the differences between new and existing fault property algorithms. 


\section{Fault property algorithms}

Two types of parameter are required to define a model of a fault system for the purposes of examining the static connectivity or flow response of a faulted sequence: those which define the geometrical scaling properties of the fault system and those which define the flow properties of the faults. Whilst the geometrical properties of faults can often be explicitly incorporated in cellular models, the flow properties of faults are incorporated implicitly as fault transmissibility multipliers. Within recent years there have been significant advances in the methods used to assign fault transmissibility multipliers. Increasingly the assignment of transmissibility multipliers is underpinned by geological parameters and methods rather than by ad hoc modifications of multipliers to provide history matches. The generation of geologically derived single phase fault transmissibility multipliers for inclusion in reservoir flow models requires predictors of fault rock thickness, fault rock permeability and the variation in these two parameters over fault surfaces (Manzocchi et al. 1999). As has been found elsewhere (Marrettt \& Allmendinger 1990; Knott 1994; Little 1995), and is confirmed by our work in Taranaki, fault rock thickness data can be collected in the field and related primarily to fault displacement with a secondary lithological control. Whilst there is wide variability in fault rock thickness at a particular throw, an appropriate average thickness can be defined and a predictor based on fault displacement with (Fig. 6) or without a lithological dependence can be derived (see Manzocchi et al. 1999). These quantitative definitions therefore provide a means of assigning fault rock thicknesses to faults with varying displacements in flow models. Definition of a meaningful predictor for fault rock permeability is a much more difficult task due to the strongly heterogeneous and anisotropic nature of fault rock. Predictors of fault permeability are necessarily based on simplified and idealised models of fault zone structure. Here we consider three permeability predictors based on the idealized fault zone structures shown in Fig. 10 ( $a, b$ and $c$ ). These fault zone structures are constructed to constrain predictors of across-fault permeability, i.e. what is the permeability encountered on a line traversing the fault ignoring details of the effect of tortuous flow paths through the fault. The first of these methods for assigning transmissibility multipliers, the Shale Gouge Ratio method, is perhaps the most conventional method available and was first applied by Manzocchi et al. (1999). We also present two new methods, a Shear Zone method and probabilistic Shale Smear Factor method, both of which can be related to the Shale Gouge Ratio method although they may in fact be more appropriate to the modeling of fault properties in heterogeneous sand-clay sequences, such as the turbidites in the Taranaki Basin.

Simplified fault zone structure models other than those described below (and illustrated in Fig. 10) have been previously described. A variety of models in which clay or shale smear thickness decreases with distance from the shale source bed have been proposed (Yielding et al. 1997). Most notable of these is the Clay Smear Potential method (Fig. 10d), in which smear thickness decreases in proportion to the square of the distance to the source bed (Lehner \& Pilaar 1997). This method has been applied to estimation of fault seal capacity (Fulljames et al. 1997) and permeability prediction (Bentley \& Barry 1991). These distance-weighted methods predict a minimum shale smear thickness, and therefore a maximum likelihood of smear disruption, midway 
between the source layer cutoffs on the footwall and hangingwall sides of a fault. Whilst smears which taper away from the source layer are common at Taranaki (Fig. 7a), examples of tapering from both source bed cutoffs are extremely rare. Figure $8 \mathrm{~b}$ shows a plot of clay smear thickness versus distance from the clay source bed, both normalized to the source bed thickness. The data demonstrate that there is no clear relationship between distance from the source bed and smear thickness and that thicknesses immediately adjacent to the source bed may be as low as those distant from the source bed. We therefore concentrate on fault zone structure models in which fault rock properties do not vary as a function of distance from source layer.

\section{Shale Gouge Ratio permeability predictor}

The Shale Gouge Ratio (SGR) method is the most widely used permeability predictor and has been applied in a number of published studies (Manzocchi et al. 1999; Childs et al. 2002; Rivenaes \& Dart 2002: Sperrevik et al. 2002). It is based on permeability constraints indicating a negative correlation between the phyllosilicate fraction within a fault rock and its permeability (Fig. 9b; Gibson 1998; Sperrevik et al. 2002; this study). The phyllosilicate fraction is equated to SGR, which is the proportion of clay (or shale) within a sequence that has moved past a point on a fault. The SGR can be calculated at any point on a fault surface from a knowledge of the fault displacement and the clay content of the faulted sequence; clay contents can be estimated either by mapping individual clay beds or by modeling Vclay variations. This SGR value is then transformed to a fault rock permeability via a relationship fitted to experimental permeability data such as the data shown in Fig. 9b. The precise nature of this relationship varies between studies (Childs et al. 2002: Sperrevik et al. 2002), a feature generally attributed to differences in factors such as the burial depth at the time of faulting and the maximum burial depth. Nevertheless the general perception is that SGR:permeability transformations should follow a negative correlation, perhaps even an approximately linear relationship on a plot of SGR against log-permeability. Previously published data have not, however, been derived from an individual outcrop study area, and it is striking that the Taranaki data, although sparse, are consistent with a straight line or slightly concave upwards curve on Fig. 9b. The SGR algorithm implicitly defines a fault rock model in which the host rock lithologies are mixed together (Fig. 10a), such that a sequence of sands and shales with a net:gross of $80 \%$ will, when faulted, produce a uniform fault rock with $20 \%$ phyllosilicate and an equivalent permeability (derived from a given SGR v. permeability transformation). Since the permeability of a random mixture is the geometric average (e.g. Gutjahr et al. 1978), a linear relationship between SGR and log-permeability, which is equivalent to the geometric average, is consistent with a fault rock model involving perfect mixing. A mixing model is not, however, necessarily appropriate in the presence of discrete smears, and two new models that incorporate these are discussed below. 


\section{Shear Zone permeability predictor}

Field observations suggest that the mixing approach embodied in the SGR method may not be appropriate to faults in the Taranaki area. Individual continuous clay smears and anastomosing zones of clay smear provide continuous layers of low permeability rock where net sand content is high and a relatively high permeability would be predicted from the SGR approach. The possibility of low permeability fault rocks (clay smears) derived from relatively low clay content sequences means that SGR cannot be considered a direct proxy for fault rock phyllosilicate content and therefore fault rock permeability. Field observations suggest, by contrast, that the contribution of host rock source layers to fault rock does not, in fact, represent mixing of sand/clay as embodied by the SGR method, and that a more appropriate method would be to attach more significance to the continuity of clay smears. An alternative end member approach to the SGR method is to consider that fault zone structure is a perfect shear zone, with no mixing between faulted units, all of which (clay and sand units) are continuous between the source layer cutoffs (Fig. 10b). In this case the fault rock would comprise an attenuated host rock stratigraphy and, in the absence of fault-related deformation processes (i.e. cataclasis, porosity collapse etc.), the across fault permeability would be the harmonic mean of the clay and sand weighted according to their relative thickness in the faulted sequence, i.e. the vertical permeability $\left(\mathrm{K}_{\mathrm{v}}\right)$ of the unfaulted sequence. Here we incorporate the effects of fault processes and the appropriate permeability is the harmonic mean of the sand and clay derived fault rock, weighted according to the thicknesses of their parent wall rocks. This method is likely to provide a relatively low permeability prediction, and is therefore a useful end member predictor, since it does not consider the possibility that clay smears are discontinuous. The method described below does acknowledge this likelihood and may well provide the most appropriate fault property predictor for sand-clay sequences.

\section{Probabilistic Shale Smear Factor permeability predictor}

A more realistic approach to clay smearing than the Shear Zone model described above, is one in which clay smears maintain continuity at relatively low displacements, becoming disrupted as displacement increases (Fig. 10c). Field observations in this and other studies (e.g. Lindsay et al. 1993) suggest that a critical ratio between fault displacement and clay source bed thickness, SSF$_{c}$, can be defined at which clay smears start to become discontinuous, e.g. the Shale Smear Factor measurements presented in Fig.8a. Such observations form the basis for developing a permeability predictor based on a probabilistic approach to evaluating continuity of clay smears; we refer to this approach as the Probabilistic Shale Smear Factor (PSSF). We define PSSF as a binary fault surface property marking the presence of one or more stochastically-placed shale smears. The smears are continuous for $\mathrm{SSF} \leq \mathrm{SSF}_{\mathrm{c}}$, and placed at a random location between the source shale layers for SSF $>\mathrm{SSF}_{\mathrm{c}}$. Since the definition of PSSF contains a stochastic component, different 
realisations will generate different PSSF distributions on the same fault surface. In this article we are not concerned with the precise details of individual realisations (see Manzocchi et al. this volume for a detailed discussion), but with the average properties of many PSSF realisations. In the following sections we develop a simple application in which these average properties are analytically defined for a single cross-section of a fault. We go on to compare the permeabilities predicted by this method with those of the SGR method and the Shear Zone (SZ) approach and also to consider when this averaged application of PSSF is appropriate and when the stochastic approach, as implemented by Manzocchi et al. (this volume), is required.

\section{Probability calculation}

In defining the PSSF parameter we consider that clay smears are continuous until they reach a critical Shale Smear Factor cutoff value $\left(\mathrm{SSF}_{\mathrm{c}}\right)$ at which they become discontinuous (Fig. 11a). Once a clay smear becomes discontinuous it maintains a constant length which is given by $\mathrm{T}\left(\mathrm{SSF}_{\mathrm{c}}-1\right)$ and is randomly located between its footwall and hangingwall source layer cutoffs. When $\mathrm{SSF}_{\mathrm{c}}$ is exceeded for a single clay smear, the probability of encountering a gap in that smear at any point between its source layer cutoffs is

$$
1-\left(T \times\left(S S F_{c}-1\right) /(D-T)\right)
$$

where $D$ is fault displacement and $T$ is the apparent source layer thickness measured along the fault trace. Note that for simplicity in the remaining discussion of PSSF we consider vertical faults offsetting horizontal layering so that $D$ is equal to the throw and $T$ is equal to the true layer thickness.

At a particular point on a fault the probability of having no smear (i.e. a gap in clay smear) is the product of Equation 1 calculated for each clay layer faulted past that point (Fig. 11b). If the SSF for any of the clay layers is lower than $\mathrm{SSF}_{\mathrm{c}}$ then the probability of a gap in the smear is zero. The results of calculations using this approach for a rhythmic sand/clay sequence in which all clay layers have the same thickness are illustrated in Fig. 12. Probabilities calculated in this way can be expressed either in terms of the likelihood of encountering a gap in the clay smear at a given point on the fault surface (Fig. 12a) or the lower likelihood that the gap occurs on a window of sand on sand juxtaposition (Fig. 12b). The second of these expressions would be appropriate for estimating reservoir connectivity. Here we are interested in predicting the permeability of the fault surface so that the first expression is appropriate. Expressed in terms of the fault surface, there is always the possibility of a gap in the clay smear once the critical clay smear cutoff is exceeded so that there is always a finite probability of a gap even when the sequence contains $100 \%$ clay; this is not the case when only sand on sand juxtapositions are considered. 
In the formulation below, the probability of encountering a clay smear is taken to be equal along the fault trace length between the upthrown and downthrown source layer cutoffs. This approach could be easily modified to incorporate a probability distribution reflecting, for example, an increased likelihood that a continuous clay smear occurs close to the clay source layer. Fieldwork in the Taranaki area, however, suggests that there is no clear systematic relationship between the proximity to a clay source layer and either the occurrence, or the thickness, of the smear.

\section{Permeability calculation}

The probability of encountering a gap at any point on the fault trace segment shown in Fig. $11 \mathrm{~b}$ is the same as the average total hole size (which would be derived from multiple realizations of randomly positioning shale smears in Fig. 11b) divided by the length of the fault trace segment. We use this observation to convert the probabilities derived above to average across-fault permeabilities. We assume that the fault segment length contains gaps in the clay smear equal to the average total hole size and we then assign clay and sand derived fault rock permeabilities to the smears and gaps respectively. The average fault rock permeability is then the arithmetic average of the shale and sand derived fault rocks, weighted according to the length of fault trace covered by the two components (Walsh et al. 1998).

\section{PSSF predictions}

Results of our calculations are shown on plots of probability of a hole in the shale smear versus the clay fraction of the faulted sequence (Fig. 12). Clearly the probability of a gap increases with decreasing $\mathrm{SSF}_{\mathrm{c}}$ (Fig. 12a). For a particular $\mathrm{SSF}_{\mathrm{c}}$ and clay (i.e. shale) fraction, the probability of encountering a gap in the smear increases with the number of beds on which the clay fraction is distributed (Fig. 12c). This is due to overlapping of clay smears reducing the length of clay-covered fault trace. Whilst the total length of smear derived from the faulted sequence is $\left(1-\mathrm{SSF}_{\mathrm{c}}\right)$ times the total clay thickness, the proportion of this length which occurs at overlaps of two or more smears, and therefore the probability of a gap, increases with the number of beds. For example, if the clay smear in Fig. 11b was derived from a single thick clay source bed rather than 5 thin source beds, the total length of clay smear would be the same, but there would be no potential for smear overlap and the probability of generating a gap in the smear would be at a minimum. Where the clay fraction occurs in a single bed then the gap probability is zero at a clay fraction $=1 / \mathrm{SSF}_{\mathrm{c}}$. On the log-linear plot of probability versus clay fraction shown in Fig 12c, the relationship for larger numbers of beds is progressively straighter.

\section{Comparison between permeability predictors}


Fault rock permeability predictions using the SGR approach are based on a correlation between clay fraction and fault rock permeability. The PSSF approach, by contrast, involves probabilistic predictions of the continuity of clay smears, or more correctly of the presence of lacunae in smears. A comparison between the SGR and PSSF methods can, however, be made on a cross-plot of clay fraction and fault rock permeability (Fig. 13). For the purposes of this comparison we assume a straight line relationship between SGR and log permeability, representing perfect mixing (grey lines in Fig. 13). The permeability input to the PSSF method is the two end member fault rock permeabilities i.e. those for fault rock derived purely from sand and from clay; in Figs 13a, $b$ these are $1 \mathrm{mD}$ and $0.0001 \mathrm{mD}$ respectively. The PSSF probability curves in Fig. 12c are converted to equivalent permeabilities in Fig. 13a. The permeability curves are bounded by the clay smear permeability, corresponding to a hole probability of zero, and the sand derived fault rock permeability corresponding to a hole probability of one. For large numbers of beds the PSSF derived permeability defines an approximately straight line, the slope of which is dependent on the $\mathrm{SSF}_{\mathrm{c}}$ (Fig. 13b). It is therefore possible to find a value of $\mathrm{SSF}_{\mathrm{c}}$ at which the PSSF permeability prediction closely matches the straight-line SGR relationship. For smaller numbers of beds $(<10)$ the non-linearity of the PSSF relationship means that correspondence between SGR and PSSF cannot be found (Fig. 13a). For typical SSF cutoffs (greater than c. 7) and low bed numbers, the PSSF predicted permeability is lower than the SGR permeability and the difference between the methods increases with decreasing bed number.

For large numbers of beds $(>10)$ it is possible to find an SSF $_{c}$ for which both the SGR and PSSF methods predict approximately the same permeabilities. This 'equivalent' $\mathrm{SSF}_{\mathrm{c}}$ value is, for simple rhythmic sequences, a function only of the difference in permeability of the two end member fault rocks. Figure $13 \mathrm{c}$ shows PSSF curves based on two sets of end-member permeabilities which together define a fault rock permeability range of 4 orders of magnitude. The curve shapes for the two permeability cases are identical and the SGR curve is most closely approximated by a $\mathrm{SSF}_{\mathrm{c}}$ of c. 10. For an increase in permeability range from 4 to 6 orders of magnitude, the 'equivalent' $S_{S F}$ increases from c. 10 to 14 (Fig. 13d).

\section{Application to a Taranaki sequence}

In the previous section we were concerned with a rhythmic sequence where the probability of encountering a hole, and therefore the average predicted permeability, is the same at all points along a fault trace with constant displacement. For non-rhythmic sequences, the probability of encountering a hole will vary along a fault trace, so the averaging technique requires some modification for application to real sequences. Here we illustrate one way that the method can be applied to provide an estimate of fault permeability for real sequences. As described above, the probability of there being no clay smear at a point on a fault surface is the product of the probabilities of a gap in each of the individual smears derived from each clay source bed. We now calculate the permeability at this point in the same way as described above. As discussed above, 
this application calculates, for each position on the fault surface, the average permeability that would be obtained from multiple realizations of a stochastic smear placement. We discuss in the following section the circumstances in which such averaging may be appropriate as opposed to those in which an explicit stochastic placement of smears is necessary for capturing the fault permeability heterogeneity. Irrespective of whether averaging is, or is not, appropriate, it is nevertheless informative to compare the results of this application of PSSF with other permeability predictors for a natural sequence.

Figure 14 shows 'triangle' diagrams (explained in Fig. 14a) contoured for permeability, constructed for an upward fining sequence within the turbidite sequence recorded at Tongaporutu. The permeability input in this case is a six order of magnitude range from $1 \mathrm{mD}$ for faulted sands through to $1 \mathrm{nD}$ for a pure faulted clay as suggested by the data in Fig. 9. The SGR permeability is again predicted using a straight-line relationship between these two end points. Comparison between the SGR based permeability prediction (Fig. 14a) and PSSF results shows the closest correspondence between these methods at an $\mathrm{SSF}_{\mathrm{c}}$ of $c .12$ (Fig. 14c). The similarity of predicted permeabilities is seen in all parts of the sequence from the relatively thickly bedded, high net:gross, base of the sequence to the finely bedded, low net:gross, top of the sequence. Only at throws equal to a small number of bed thicknesses does the similarity between the predicted permeabilities break down. Figure 15 shows that for fault throws greater than $5 \mathrm{~m}$ there is an approximately linear relationship between the PSSF-predicted permeability and clay (i.e. shale) fraction at $\mathrm{SSF}_{\mathrm{c}}=12$. At throws lower than $5 \mathrm{~m}$, where only a few beds have moved past a point on a fault, the permeability values drop well below this straight line.

The across-fault permeabilities predicted on the basis of the shear zone model for the sequence recorded at Tongaporutu are shown in Fig. 15. The predicted permeabilities are calculated from the harmonic mean of the sand and clay derived fault rock permeabilities, weighted according to the thickness of sands and clays that have passed a point on the notional fault. Where the SGR approach to permeability assignment produces estimates of fault permeability close to the upper limit of those predicted by the PSSF application used here, the shear zone method provides a curve towards the lower bound of the PSSF data. The PSSF application described here uses a simple approach in which the permeability of a fault containing a continuous clay smear is that of the clay smear and ignores the influence of other fault rock components. This simple approach, when applied to very high values of $\mathrm{SSF}_{\mathrm{c}}$, i.e. very thin smears, will lead to unrealistically low predictions of permeability. In the shear zone model of fault zone structure, SSF $_{c}$ is effectively infinite but this model does acknowledge the contribution of non-clay derived fault rocks and does not therefore generate unrealistically low permeabilities. This shear zone model therefore provides a likely lower bound to permeability predictions derived from the simple PSSF application.

\section{Discussion}


The curves in Figs $12 \& 13$ are for probabilities and average permeabilities but give no indication of the validity of these averages or the ranges of values about them. To define the spread of values about the mean we have conducted stochastic modeling of the system illustrated in Fig. 11 and discussed in the accompanying text. Modelling results are expressed in terms of the total length of hole in the clay smear, expressed as a fraction of the length of fault trace over which it is measured (i.e. the sampling window). Results are shown in Fig. 16 for cases in which the sampling window is equal to the fault throw. Vertical bars on Fig. 16 are the $5^{\text {th }}$ and $95^{\text {th }}$ percentile from 1000 realizations for particular combinations of smear length and number of beds. The curves illustrate the reduction in total hole length with increase in both the number of beds within the throw window (equal to the number of smears and corresponding to an increase in shale fraction) and the length of smears. In addition the range of hole sizes increases with decreasing number of beds and increasing smear length. There are clearly parts of the curves for which an averaging approach to the calculation of total hole fraction is appropriate, e.g. for 200 beds and a smear length/throw ratio of less than 0.01 , and areas where it is inappropriate and large numbers of realisations have a zero hole length e.g. for 200 beds and a smear length/throw ratio greater than 0.02 . The dashed curve in Fig. 16 connects cases where the population of hole sizes has a coefficient of variation of 0.5 ; above this this curve the coefficient of variation is less than 0.5 and the averaging approach is thought to be appropriate (see below).

In the discussion so far we have been concerned with defining situations in which the total hole length, and therefore permeability, can be meaningfully averaged over a length of fault trace equal to the fault throw. In real applications, the length scale on which it is necessary to define permeability variability is likely to be significantly smaller (or potentially larger) than the throw, for example the height of a grid block in a reservoir model. To examine the systematics for fault trace lengths other than the fault throw, hole sizes were measured in fault trace windows of varying length on the stochastically modeled faults. The results of these analyses, for a system of 20 offset beds, are shown as contours of the mean of fractional hole sizes measured over the fault window (Fig. 17a) and the coefficient of variation (Cv) of these fractional hole sizes (Fig. 17b). The data demonstrate that the mean hole fraction within the sample window is independent of window length, however the $\mathrm{Cv}$ of hole size is strongly dependent on the window length. As the window length decreases, the $\mathrm{Cv}$ increases, and the range of likely hole sizes increases so that the assignment of an average value becomes progressively less representative of the system. This lack of representativeness is most clearly illustrated when the large majority of realizations have a hole size of zero but the mean is not zero and therefore not representative of the most likely permeability; in these cases the $\mathrm{Cv}$ is very high. The situations for which the mean total hole fraction is representative of clay smear distribution on the model fault surface can be defined on the basis of the Cv of fractional hole size. Following Corbett \& Jensen (1992), who defined this value as the boundary between homogeneous and heterogeneous systems, we take $\mathrm{Cv}=0.5$ as the threshold above which we consider the uncertainty in permeability large enough to warrant stochastic placement, rendering the single, average permeability value calculated with the probabilistic approach too homogeneous. Curves for a $\mathrm{Cv}$ of 0.5 for different numbers of beds 
within a throw window are shown in Fig. 17c. These curves demonstrate that the clay smear length/throw ratio at which a $\mathrm{Cv}$ of 0.5 is reached is lower for higher numbers of beds (corresponding to a higher shale fraction) because, for a given smear length, the numbers of realizations with a continuous smear will be higher for higher numbers of beds. The use of Fig. 17c in determining whether an average or stochastic application of the PSSF approach is appropriate in particular circumstances is illustrated by considering an example of a fault with a throw of $50 \mathrm{~m}$, offsetting a sequence containing twenty $0.2 \mathrm{~m}$ thick clay beds. If the window length of interest (e.g. grid cell height) is $5 \mathrm{~m}$, then for an $\mathrm{SSF}_{\mathrm{c}}$ of 5 , the smear length is four times the bed thickness, i.e. $0.8 \mathrm{~m}$. The smear length/throw ratio is 0.016 and the fault plots at the point labeled $X$ in Fig. $17 \mathrm{c}$, to the left of the curve for 20 beds and so an averaging approach is appropriate. If however the SSFc is considered to be 12, then the smear length/throw ratio is 0.03 (point $Y$ on Fig. 17c) and an averaging method is inappropriate.

The approaches to fault property prediction in the SGR and PSSF methods are, on the face of it, very different. In the SGR method an average property is assigned to all parts of a fault trace between clay source layer cutoffs, while in the PSSF method, once the $\mathrm{SSF}_{\mathrm{c}}$ is exceeded the fault trace comprises low permeability smears that are punctuated by high permeability gaps. In terms of the predicted permeability of a length of fault trace between a single pair of source layer cutoffs, the SGR method predicts a smooth increase in permeability with increasing displacement, whilst the PSSF approach predicts a sudden step from the permeability of clay fault rock to that of sandderived fault rock. Nevertheless, despite these apparently stark differences, the results generated from both of these methods may become effectively the same for particular $\mathrm{SSF}_{\mathrm{c}}$ ranges when the fault throw is several times larger than bed thickness and many shale layers are present in the averaging window. For the Taranaki faults, where the difference in permeability between sand and clay derived fault rocks is up to 6 orders of magnitude, this equivalence occurs at an $\mathrm{SSF}_{\mathrm{c}}$ of 12 to 14; this range is higher than, but not dissimilar to, the SSF cutoffs measured at outcrop. The PSSF application described above assumes that once a smear has become discontinuous it stops lengthening; however, it is far more likely that smears will continue to lengthen by shearing with increased fault displacement. It is therefore likely that the effective $\mathrm{SSF}_{\mathrm{c}}$ which best defines the permeability variation on a fault will be higher than that measured from the clay smear continuity of individual smears seen in outcrop and higher than that which produces similar permeabilities to the SGR approach. If, for instance, shale smears increased their length by $50 \%$ due to continued shearing following smear rupture, then an effective $\mathrm{SSF}_{\mathrm{c}}$ of $c .12$ would be appropriate for the Taranaki area and the PSSF prediction of permeability would be very similar to that of the SGR prediction; if continued shearing provided a two-fold increase in smear length then the PSSF prediction would be significantly lower than that of the SGR prediction.

The PSSF approach acknowledges the effects of changing correlation lengths on permeability prediction. The method includes the on/off behaviour of clay smears observed in the field when fault displacements are similar to bed thicknesses but also provides an averaged permeability prediction when fault displacements are significantly higher then bed thicknesses. The PSSF 
method therefore provides a richer permeability predictor than the SGR method providing the opportunity to capture some of the scale-dependent permeability variations associated with faulting.

\section{Conclusions}

Correlations between fault displacement and fault rock thickness from the Taranaki basin and elsewhere are entirely consistent and provide a means of predicting fault rock thicknesses for fault property modeling.

Faulting causes a reduction in grain size causing a maximum observed permeability reduction of 2 orders of magnitude.

Clay smears are a common feature of these fault zones, with smears which are generally continuous when the fault throw is less than eight times the clay source rock thickness.

Since the difference in permeability between the different lithologies within a sequence is several orders of magnitude larger than the difference in permeability between a fault rock and its parent host rock, the effect of smearing of low permeability rocks, such as clays (which have permeabilities in the nanoDarcy range), along a fault therefore has a much greater impact on fault permeability than other fault-related processes (i.e. cataclasis, porosity collapse, etc.). This and other observational data provide support for the application of certain shale smear algorithms, such as shale smear factor, in fault property modeling.

The permeabilities of fault rocks from Taranaki subscribe to approximately straight negative correlations between phyllosilicate content and log fault rock permeability, a correlation which provides support for the application of the Shale Gouge Ratio (SGR) fault rock permeability predictor within upscaled reservoir models in which clay layers are not explicitly modeled.

An alternative newly developed fault rock permeability predictor is the Shear Zone (SZ) model, in which fault rock permeabilities are calculated as the harmonic mean of clay and sand derived fault rock, weighted according to the thicknesses of sand an clay in the host rock stratigraphy. This approach provides relatively impermeable faults but nevertheless represents a useful end-member permeability predictor.

The predictor which best honours the fault zone structure in Taranaki is believed to be the Probabilistic Shale Smear Factor (PSSF) model. In the PSSF method applied here, fault rock permeabilities are predicted from the probabilities of generating gaps within otherwise continuous smears. PSSF derived permeabilities span the range between the SGR and the SZ methods.

In circumstances where more than $c$. 10 beds have been offset across a fault, there is a linear relationship between the permeabilities predicted from the SGR and PSSF methods, indicating a 
broad equivalence between the two approaches. The PSSF method nevertheless predicts a more heterogeneous and realistic fault rock structure than the SGR approach, and is therefore more consistent with outcrop constraints.

Results of one simple application of PSSF to faults in a rhythmically layered sequence, allows circumstances in which it is appropriate to apply a PSSF averaging approach to the estimation of fault permeability, to be distinguished from those when a stochastic approach is required. 
We thank the following companies and their representatives for supporting our ITF brokered FIFT research project entitled 'Quantitative characteristics of faults and fault zones and their impact on flow within deep water turbidites, onshore New Zealand': Hess, BG Energy Holdings, BP Exploration, ConocoPhillips, Kerr-McGee North Sea, Shell, Statoil and Total. We also thank Peter Haughton and Peter King, our sedimentology partners in the project, and other members of the Fault Analysis Group. We are grateful to Malcolm Arnot at GNS who conducted the permeability measurements using the mini-permeameter and Tom Culligan at UCD for thin section preparation. We thank Richard Gibson and Eddie McAllister for their constructive reviews and David Barr for his editorial handling. 


\section{References:}

Bentley, M. R. \& Barry, J. J. 1991. Representation of fault sealing in a reservoir simulation: Cormorant Block IV, UK North Sea. SPE 22667. 66th Annual Technical Conference \& Exhibition of the Society of Petroleum Engineers, Dallas, Texas, 119-126.

Browne, G. H., McAlpine, A. \& King, P. R. 1996. An outcrop study of bed thickness, continuity and permeability in reservoir facies of the Mt. Messenger Formation, North Taranaki. New Zealand Petroleum Conference Proceedings, 10-13 March 1996, Volume 1. Ministry of Economic Development, Wellington, 154-163.

Browne, G. H. \& Slatt, R. M. 2002. Outcrop and behind-outcrop characterization of a late Miocene slope fan system, Mt. Messenger Formation, New Zealand. Bulletin of the American Association of Petroleum Geologists, 86, 841-862.

Childs, C., Manzocchi, T., Nell, P. A. R., Walsh, J. J., Strand, J. A., Heath, A. E. \& Lygren, T. H. 2002. Geological implications of a large pressure difference across a small fault in the Viking Graben. In: Koestler, A. G. \& Hunsdale, R. (eds) Hydrocarbon Seal Quantification. Special Publication of the Norwegian Petroleum Society, 11, 187-201.

Corbett, P. W. M. \& Jensen, J. L. 1992. Estimating mean permeability - how many readings do you need? First Break, 10, 89-94.

DeMets G.R.G. \& Vogt, P. 1994. Location of the Africa-Australia-India triple junction and motion between the Australian and Indian plates - results from an aeromagnetic investigation of the Central Indian and Carlsberg Ridges. Geophysical Journal International, 119, 893-930.

Fulljames, J. R., Zijerveld, L. J. J. \& Franssen, R. C. M. W. 1997. Fault seal processes: systematic analysis of fault seals over geological and production time scales. In: Moller-Pedersen, P. \& Koestler, A. G. (eds) Hydrocarbon Seals, Importance for exploration and production. Special Publication of the Norwegian Petroleum Society, 7, 51-59.

Gibson, R. G. 1998. Physical character and fluid-flow properties of sandstone-derived fault zones. In: Coward, M. P., Daltaban, T. S. \& Johnson, H. (eds) Structural Geology in Reservoir Characterisation. Geological Society, London, Special Publication, 127, 83-97.

Gutjahr, A.L., Gelhar, L.W., Bakr, A. A, \& Macmillan J.R., 1978. Stochastic analysis of spatial variability in subsurface flows 2 . evaluation and application. Water Resources Research, 14, 953-959.

Harris, D., Yielding, G., Levine, P., Maxwell, G., Rose, P. T. \& Nell, P. 2002. Using Shale Gouge Ratio (SGR) to model faults as transmissibility barriers in reservoirs: an example from the Strathspey Field, North Sea. Petroleum Geoscience, 8, 167-176.

Hull, J. 1988. Thickness-displacement relationships for deformation zones. Journal of Structural Geology, 10, 431-435.

King, P. R. \& Thrasher, G. P. 1992. Post-Eocene development of the Taranaki Basin, New Zealand; convergent overprint of a passive margin. In: Watkins, J. S., Zhiqiang, F. \& McMillen, K. J. (eds) Geology and Geophysics of Continental Margins. American Association of Petroleum Geologists Memoir, 53, 93-118. 
King, P.R., \& G.P. Thrasher 1996. Cretaceous-Cenozoic geology and petroleum systems of the Taranaki Basin, New Zealand. Institute of Geological and Nuclear Sciences Monograph, 13.

King, P.R., Scott, G.H., \& Robinson, P.H. 1993. Description, correlation and depositional history of Miocene sediments outcropping along the north Taranaki coast. Institute of Geological and Nuclear Sciences Monograph, 5.

Knott, S. D. 1994. Fault zone thickness versus displacement in the Permo-Triassic sandstones of NW England. Journal of the Geological Society, 151, 17-25.

Lehner, F. K. \& Pilaar, W. F. 1997. On a mechanism of clay smear emplacement in synsedimentary normal faults. In: Moller-Pedersen, P. \& Koestler, A. G. (eds) Hydrocarbon Seals, Importance for exploration and production. Special Publication of the Norwegian Petroleum Society, 7, 39-50.

Lindsay, N. G., Murphy, F. C., Walsh, J. J. \& Watterson, J. 1993. Outcrop studies of shale smears on fault surfaces. In: Flint, S. \& Bryant, A. D. (eds) The geological modelling of hydrocarbon reservoirs and outcrop analogues. International Association of Sedimentology, 15, 113-123.

Little, T. A. 1995. Brittle deformation adjacent to the Awatere strike-slip fault in New Zealand: faulting patterns, scaling relationships, and displacement partitioning. Bulletin of the Geological Society of America, 107, 1255-1271.

Manzocchi, T., Walsh, J.J., Nell, P.A.R. \& Yielding, G. 1999. Fault transmissibility multipliers for flow simulation models. Petroleum Geoscience, 5, 53-63.

Manzocchi et al. (this volume).

Marrettt, R., Allmendinger, R. W. 1990. Kinematic analysis of fault-slip data. Journal of Structural Geology, 12, 973-986.

Nicol, A., Walsh, J., Berryman, K. \& Nodder, S. 2005. Growth of a normal fault by the accumulation of slip over millions of years. Journal of Structural Geology, 27, 327-342.

Pickering, K. T., Clark, J. D., Smith, R. D. A., Hiscott, R. N., Ricci Lucci, F. \& Kenyon, N. H. 1995. Architectural element analysis of turbidite systems, and selected problems for sand-prone deep-water systems. In: K. T. Pickering, R. N. Hiscott, N. H. Kenyon, F. Ricci Lucci and R. D. A. Smith (eds) Atlas of Deep Water Environments: Architectural Styles in Turbidite Systems. Chapman and Hall, London, 1-10.

Reches, Z. \& Dieterich, J. H. 1983. Faulting of rocks in three-dimensional strain fields. 1. Failure of rocks in polyaxial, servo-control experiments. Tectonophysics, 95, 111-132.

Rivnaes, J. C. \& Dart, C. 2002. Reservoir compartmentalisation by water-saturated faults - Is evaluation possible with today's tools? In: Koestler, A. G. \& Hunsdale, R. (eds) Hydrocarbon Seal Quantification Special Publication of the Norwegian Petroleum Society, 11, 173-186.

Robertson, E. C. 1983. Relationship of fault displacement to gouge and breccia thickness. American Institute of Mining Engineering Transactions, 35, 1426-1432.

Sperrevik, S., Gillespie, P. A., Fisher, Q. J., Halvorsen, T. \& Knipe, R. J. 2002. Empirical estimation of fault rock properties. In: Koestler, A. G. \& Hunsdale, R. (eds) Hydrocarbon Seal Quantification Special Publication of the Norwegian Petroleum Society, 11, 109-126. 
Thrasher, G.P., King, P. R. \& Cook R. A. 1995. Taranaki Basin petroleum atlas. 50 maps plus booklet. Institute of Geological \& Nuclear Sciences Ltd, Lower Hutt, New Zealand.

Walsh, J.J., Watterson, J., Heath, A.E. \& Childs, C. 1998. Representation and scaling of faults in fluid flow models. Petroleum Geoscience, 4, 241-251.

Yang, Y.L. \& Aplin, A.C. 1998. Influence of lithology and compaction on the pore size distribution and modelled permeability of some mudstones from the Norwegian Margin. Marine and Petroleum Geology, 15, 163-175.

Yang, Y.L. \& Aplin, A.C. in press. Permeability and Petrophysical Properties of Thirty Natural Mudstones. Journal of Geophysical Research.

Yielding, G., Freeman, B. \& Needham, D. T. 1997. Quantitative fault seal prediction. Bulletin of the American Association of Petroleum Geologists, 81, 897-917. 


\section{Figure captions}

Fig. 1. Maps showing the New Zealand plate boundary (inset map), late Miocene and Pliocene to Pleistocene normal faulting in the Taranaki Rift region (stippled area in main map) and the locations of the outcrops and 3D seismic data examined for this study. The main map is modified from King \& Thrasher (1996). The locations of cross sections A-A' (modified from Thrasher et al., 1995) and B-B' (King \& Thrasher 1996) across the northern and southern ends of the rift are shown. Inset map shows locations of active volcanoes (filled triangles), while the filled arrow shows the relative plate motion vector from DeMets et al. (1994). The locations of the coastal outcrop studied and a 3D seismic reflection survey which covers the Ngatoro and Kaimiro oil and gas fields are shown. The Cape Egmont Fault is labelled CEF on cross-section B-B'.

Fig. 2. Geological map of the Taranaki study area (outlined), together with the main localities referred to in text.

Fig. 3. Selected photographs illustrating some of the common fault rock types encountered in Taranaki. (a) Fault with throw of $1.8 \mathrm{~m}$ in siltstones in the White Cliffs (1.5 km north of Pukearuhe; see Fig. 2). The fault comprises thin anastomosing bands of dark fine grained silt/clay. (b) Deformation bands in porous sandstones from Tongaporutu River section stand proud of the outcrop face. The width of these deformation bands can be several times larger than the fault displacement which individually is generally mm-scale. (c) Fault with throw of $c .60 \mathrm{~cm}$ contained within medium bedded sand/clay sequence at Tongaporutu. A continuous clay smear connects the footwall and hangingwall cutoffs of an offset clay unit. The clay smear varies in thickness partly arising from synthetic Riedel shears within the fault zone. (d) A $50 \mathrm{~cm}$ wide zone of deformation bands associated with a $5 \mathrm{~m}$ throw fault in fine sandstones at Tongaporutu.

Fig. 4. Photographs illustrating the range of fault rocks developed within a large, $30 \mathrm{~m}-40 \mathrm{~m}$ throw, fault offsetting a sequence of fine sands and silts at Omahu Pa $(2 \mathrm{~km}$ north of Tongaporutu, see Fig. 2). The $2.5 \mathrm{~m}$ wide fault zone dips to the right in (a). There are four main slip surfaces and details of each are shown in (b), (c), (d) and (e) at the locations indicated. The fault zone contains a large lens of fine sandstone (between slip surfaces arrowed $d$ and $g$, internally deformed by minor antithetic and synthetic slip surfaces e. This lens is bounded on both sides by slip surfaces comprising mainly clay rich fault rock. (b) Zone of dark grey clay rich bands (upper left to lower right corner of photograph). The slip surface at this location is intersected by synthetic Riedel shears which offset the footwall sandstones and are seen as thin deformation bands. (c) Anastomosing seams of dark clay rich fault rock. (d) Slip surfaces arrowed d (top left to bottom right of photograph) and c (20 cm to the left). The right slip surface comprises a $1 \mathrm{~cm}$ thick, dark grey, clay gouge overlain by a layer of quartz cemented siltstone breccia. (e) Dark, clay rich deformation bands within the fine sandstone lens in the centre of the fault zone. (f) Hand sample showing the layered nature of the fault rock, the different layers derived from different source lithologies. The 
lighter coloured layers are clay smears derived from mudstone source beds. (g) A $1 \mathrm{~cm}$ thick clay gouge (arrowed) overlain by $\sim 10 \mathrm{~cm}$ of foliated siltstone and lenses of strongly cemented siltstone breccia (labelled br). The rectangle outlines the location of the hand sample shown in (f).

Fig. 5. Hand samples and thin section photographs (plane polarised light) of shear bands in medium grained sandstones from (a) a deformation band (displacement $<1 \mathrm{~cm}$ ) at Tongaporutu River and (b) a deformation band from within a large displacement fault (c. $12 \mathrm{~m}$ throw), c. 500m south of Tongaporutu. The offset on both deformation bands is small enough that the fault rock is sourced from the adjacent host rock. The host sandstones are immature with a significant proportion of feldspar (c. 10\%) and feldspar grains altered to phyllosilicate. There is no clear evidence of reduction in quartz grain size relative to the host sandstones but there is a general grain size reduction together with an increase in the proportion of clay matrix. The brown colour in (a) is due to the presence of haematite. The permeability of the fault rock in (a) is c. $2 \mathrm{mD}$ while that of the host rock is in excess of $100 \mathrm{mD}$.

Fig. 6. Mean fault rock thickness versus throw for 420 fault traces. Mean thickness was estimated over the accessible fault trace length which typically extends $4 \mathrm{~m}$ from the base of the sea-cliff. The data are subdivided according to facies and the appropriate facies classes of Pickering et al. (1995) are given in brackets.

Fig. 7. Clay smears from thin to medium bedded turbidites. (a) An example of a clay smear which tapers downwards from the clay rich source rock in the footwall: Awaawaroa, between Mokau and Tongaporutu; Fig. 2. Fault displacement is $c .8 \mathrm{~cm}$. (b) Complex clay smear thickness distribution on fault with displacement of $1.2 \mathrm{~m}$, Tongaporutu. Clays are highlighted in blue on inset diagram. (c) Fault strand with continuous clay smear (arrowed) formed by amalgamation of smears derived from several source layers, Awaawaroa. The total fault displacement is in the range $8 \mathrm{~m}$ to $12 \mathrm{~m}$.

Fig. 8. (a) Shale Smear Factor (SSF) versus minimum clay smear thickness plot for faults offsetting thin $(1 \mathrm{~cm}-20 \mathrm{~cm})$ clay layers at Mokau and Tongaporutu. The shale smear factor is the ratio of fault displacement to apparent thickness of clay source layer, i.e. as measured along the fault trace. (b) Profiles of clay smear thickness versus distance from the clay source layer for 15 clay smears. Both axes are normalised to the thickness of the source layer and distance is to the nearer source layer cutoff so that the profiles reflect at the midpoint between cutoffs.

Fig. 9. (a) Grain size versus permeability plot subdivided according to facies and into fault ( $x$ ) and host rock (o). Tie lines connect permeability measurements for host rocks and fault rock derived directly from those host rocks. (b) Permeability versus percentage phyllosilicate plot for fault (red) and host rocks (black). 
Fig. 10. Idealised fault zone structures implicit in the three fault rock permeability predictors considered in this paper and one additional method. (a) Shale Gouge Ratio method in which wall rocks are mixed to provide a homogeneous fault rock. (b) Simple Shear Zone method where the fault permeability is the thickness weighted harmonic average of the offsets wall rocks. (c) Probabilistic Shale Smear Factor method in which initially continuous shale smears become discontinuous with increasing displacement. (d) Clay Smear Potential method where the clay smear thins progressively with distance from the source bed cutoff.

Fig. 11. (a) Calculation of Probabilistic Shale Smear Factor for a single layer. (b) For multiple source layers (i) shale smears located between upthrown and downthrown source layer cutoffs on a fault trace length equal to the fault throw (ii) are combined to provide a net probability of a gap in the smear (iii) equivalent to the average hole size which would be derived from multiple realizations expressed as a fraction of the throw window.

Fig. 12. Plots of shale fraction versus probability of a hole in a shale smear. (a) Curves for different SSF cutoff values (labelled) for 50 and 5 offset beds. Curves for 50 beds are coloured according to SSF while equivalent curves for five beds are shown black. (b) Curves for 50 offset beds for different SSF cutoffs. Probabilities in this case are calculated for areas of sand on sand juxtaposition (see text). (c) Curves for different numbers of offset beds for shale smear cutoffs of 8 and 5 . Curves for SSF = 8 are coloured and labelled according to number of beds and equivalent curves for SSF $=5$ are shown black.

Fig. 13. PSSF predicted permeability versus shale fraction plot for (a) an $\mathrm{SSF}_{\mathrm{C}}$ of 8 and variable numbers of beds (b) 50 beds and variable SSFc and (c and d) 50 beds and variable SSFc for different permeability end points. The large grey dots are the pure sand and pure shale end points and the thick grey line is the straight line SGR permeability predictor between these points.

Fig. 14. 'Triangle' diagrams of depth versus throw contoured for predicted permeability. The triangle diagram shows the area of juxtaposition of a sequence offset across a notional fault with a throw which varies between zero and that of the sequence as illustrated in the inset to (a). The sequence of sands and shales used to construct the triangle diagrams is shown on the right of the figure: this sequence is equivalent to that found on the southern side of the Tongaporutu River. Permeabilities are in mDarcy (linear scale). Plot (a) is for permeabilities calculated using the SGR approach while ( $\mathbf{b}$ to $\mathbf{d}$ ) are calculated using the PSSF approach for different values of SSFc.

Fig. 15. PSSF predicted permeability versus shale fraction plot for the sequence shown in Fig. 14. The dots are derived from individual points on the triangle diagram in Fig. 14 and are colour coded according to throw. Also shown are PSSF permeability curves for a rhythmically bedded sequence of 50 beds and variable SSFc. 
Fig. 16. Plots of the total length of hole in a clay smear as a fraction of fault throw against smear length/throw for five different numbers of beds. Curves are shown for the mean hole size and vertical bars are the $5^{\text {th }}$ and $95^{\text {th }}$ percentiles of the distribution.

Fig. 17. Contours of (a) mean hole fraction as a fraction of the sample window length and (b) coefficient of variation $\mathrm{C} v$ of hole fraction on a plot of window length/throw versus smear length/throw. The mean values and $\mathrm{Cv}$ at each point on the plots are calculated for 1000 realisations of a system with 20 offset beds. (c) Curves of $\mathrm{Cv}=0.5$ calculated for systems with 2, 5 , 20,50 and 200 offset beds. The points labeled $X$ and $Y$ are discussed in the text. 


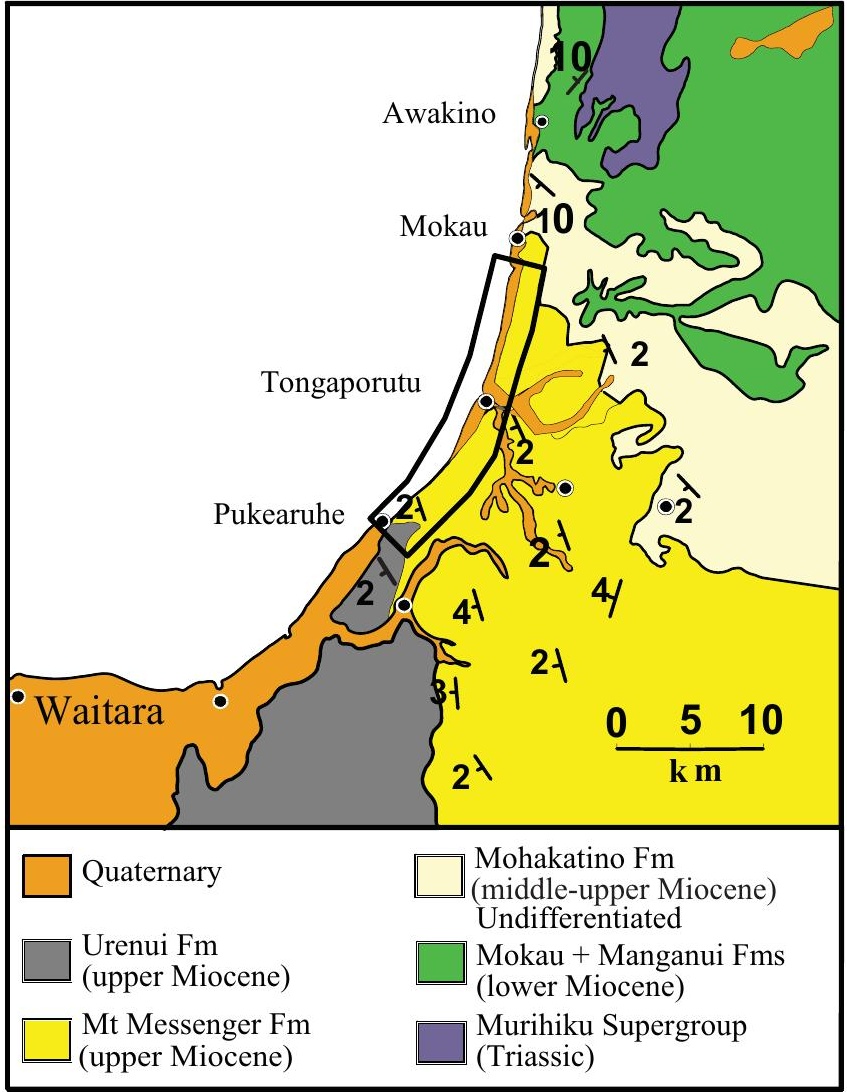




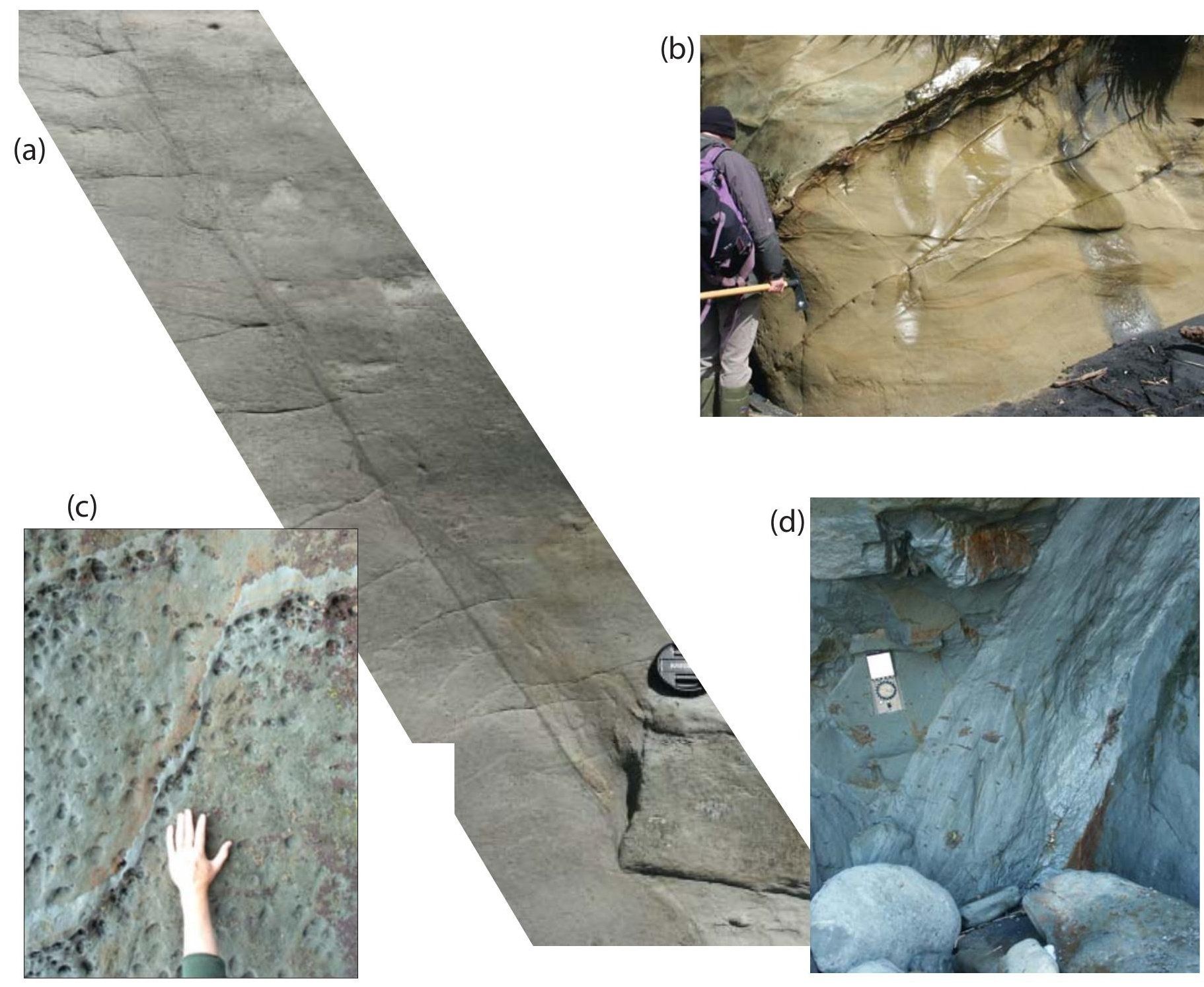




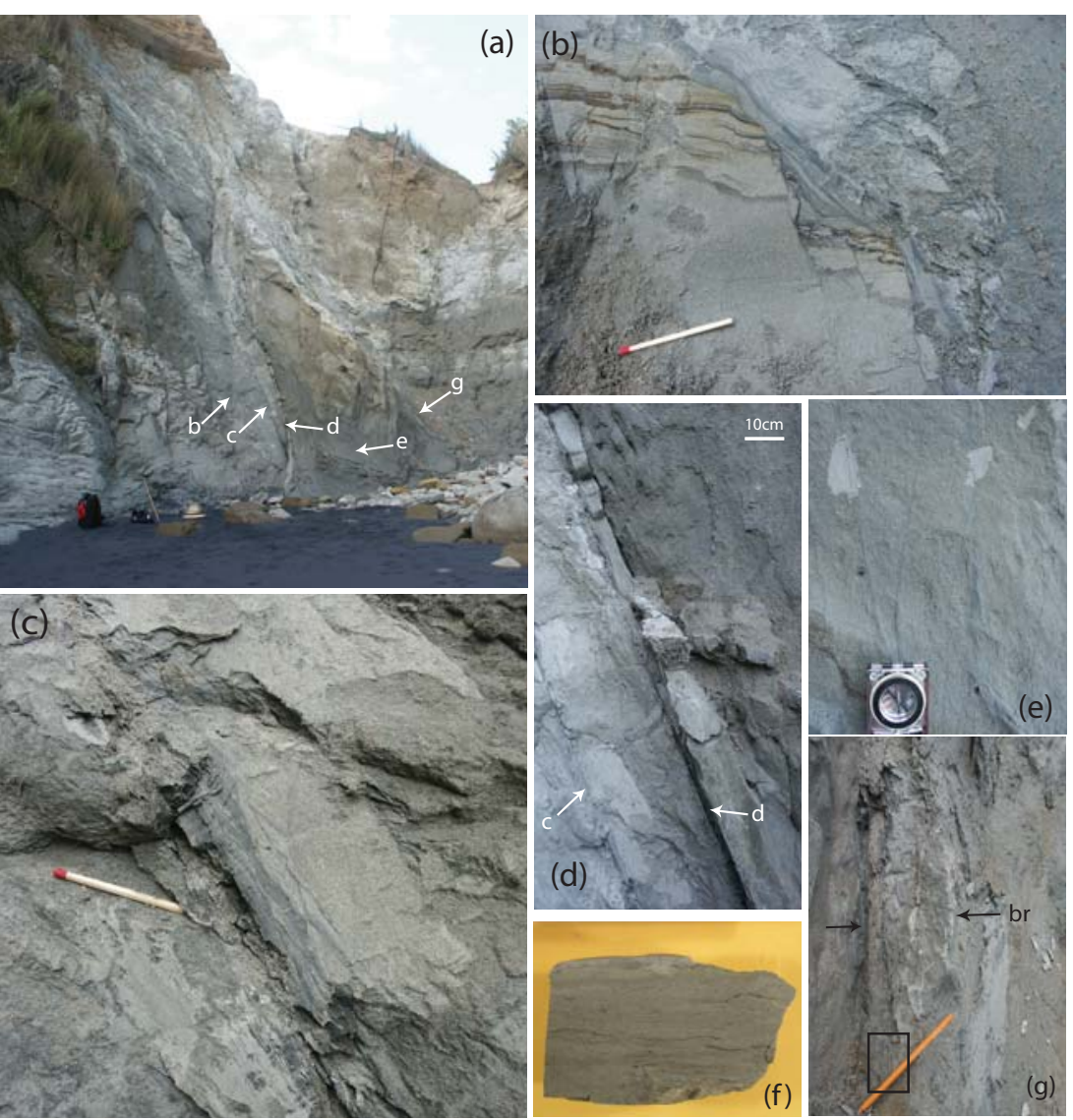




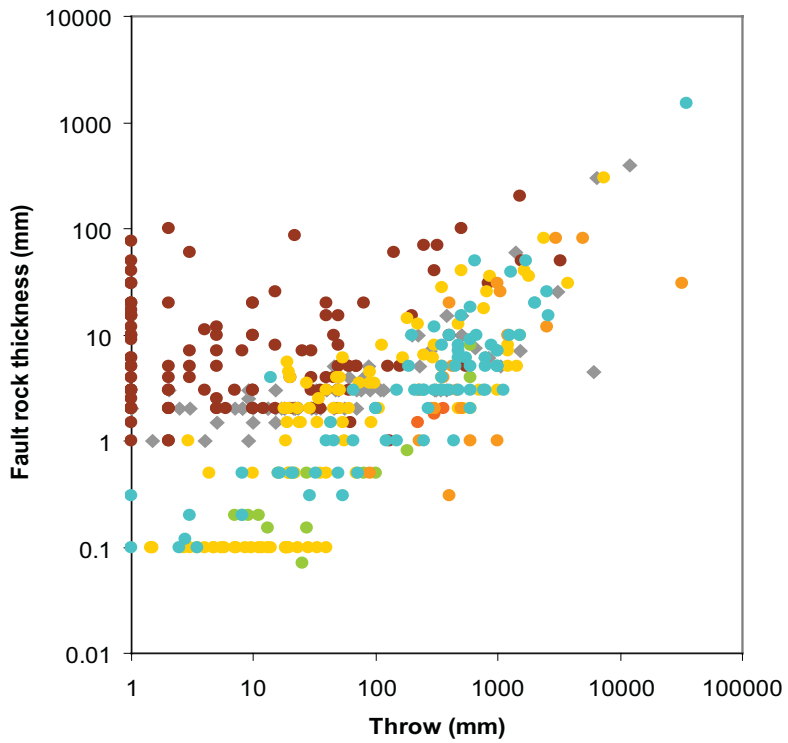

- Interbedded channel levee (C2.3, D2.3)

- Massive sandstone (B1.1, B2.1)

- Mustones $w$ thin silt - slumped \& bedded (E2.2, F2.1)

- Multistory channels (B1.1, A2.3)

Thick bedded (up to $2 \mathrm{~m}$ ) sands (C2.2)

- Thin bedded sst, sts \& mst (C2.3, D2.3)

White cliffs North cycles (C2.3, D2.3) 

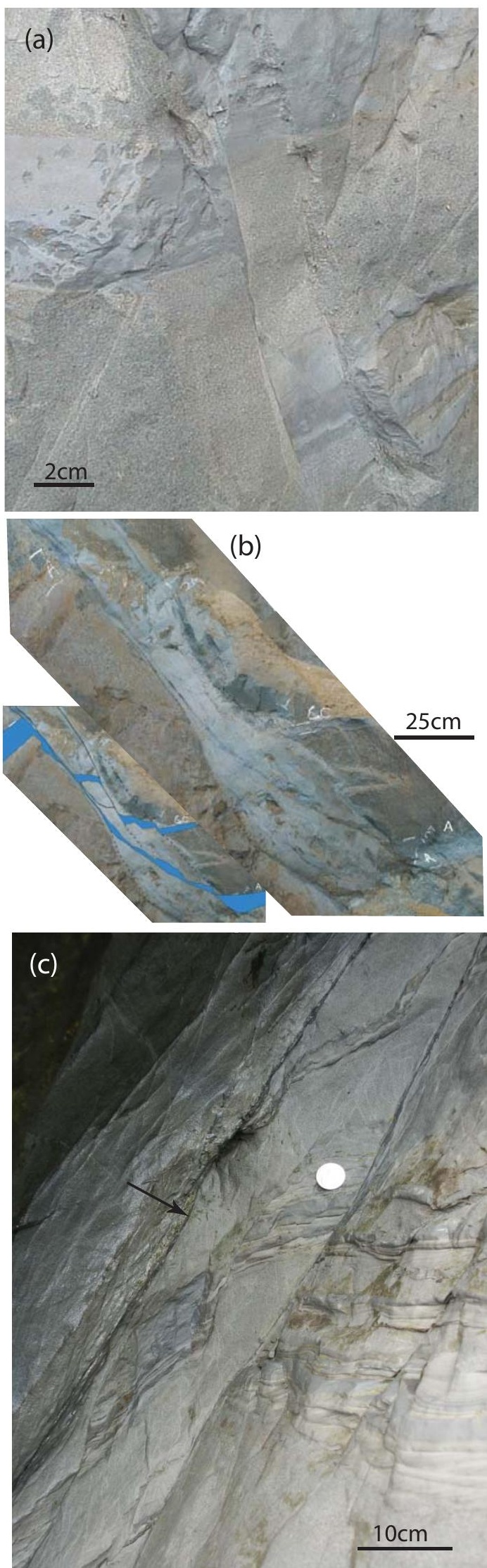


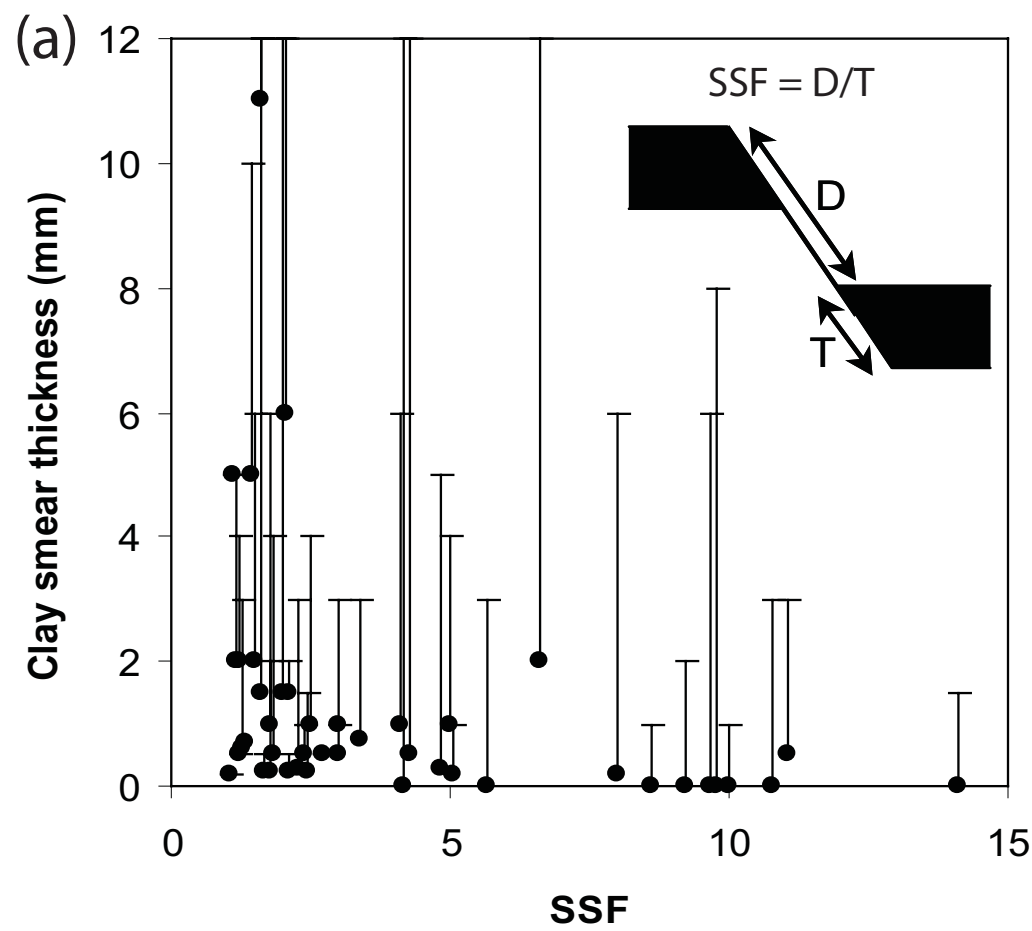

(b)

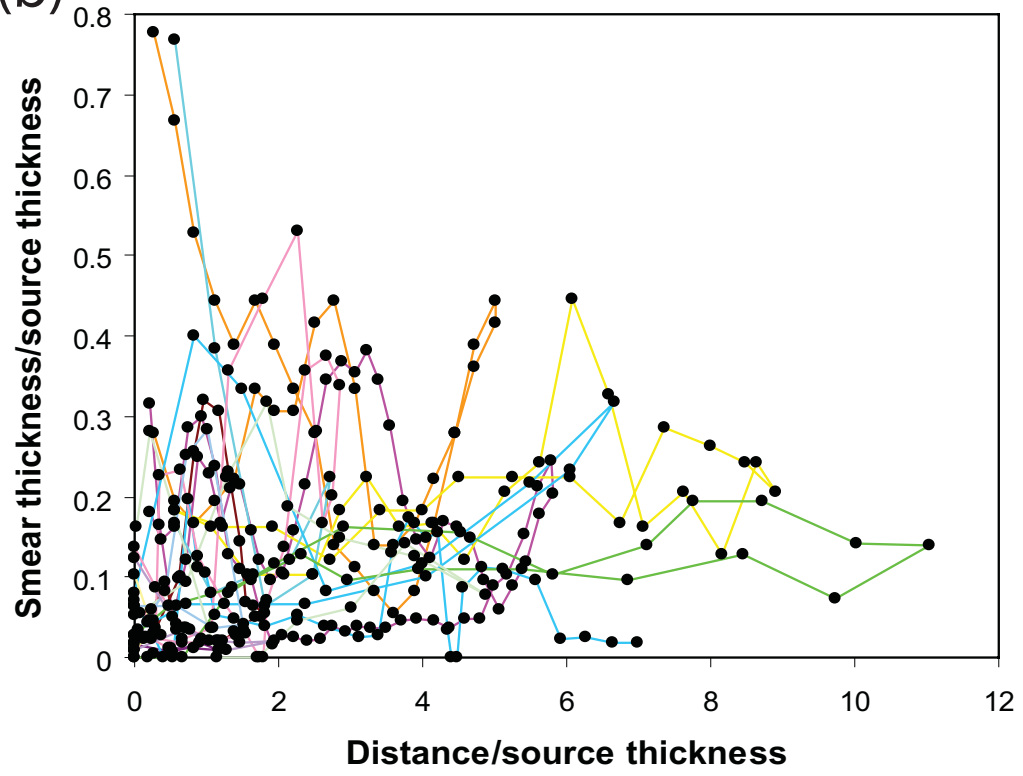



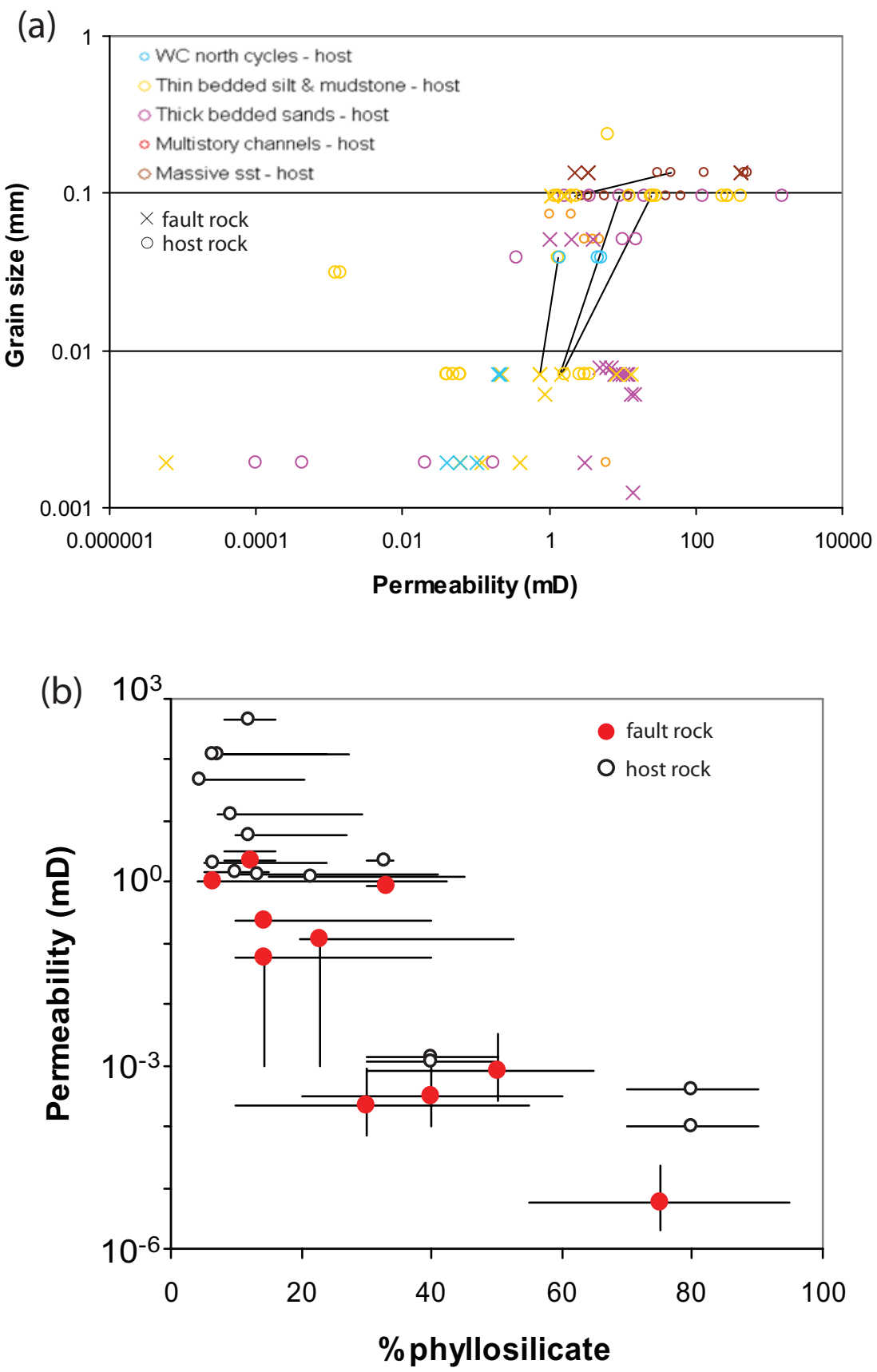


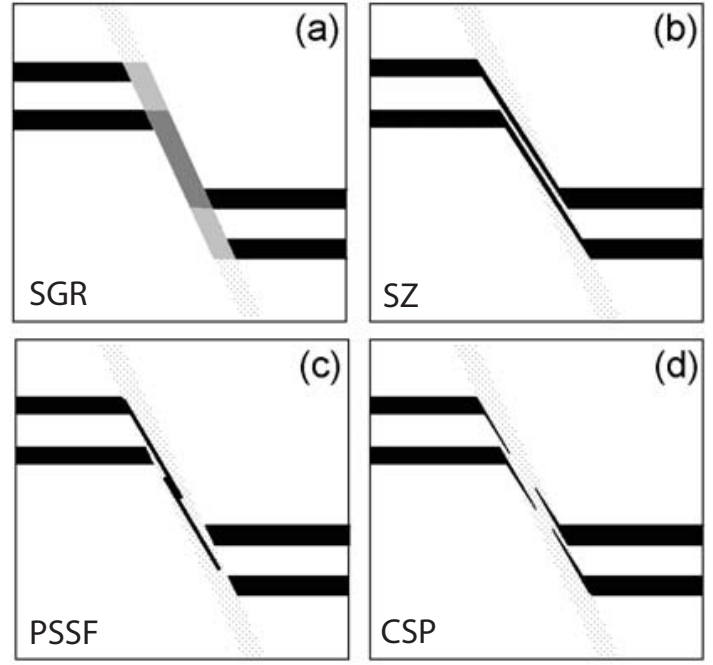


(a)

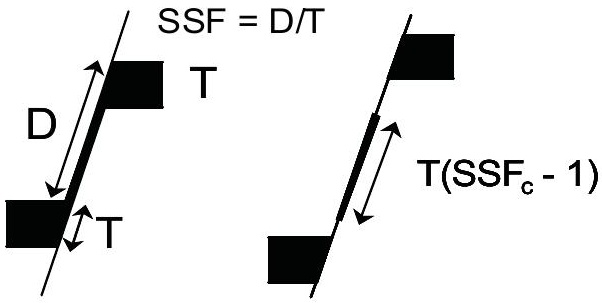

$\mathrm{SSF}<\mathrm{SSF}_{\mathrm{c}}$

$\mathrm{SSF}>\mathrm{SSF}_{\mathrm{c}}$

(b)

(i)

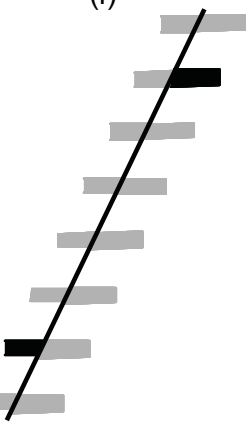

(ii)

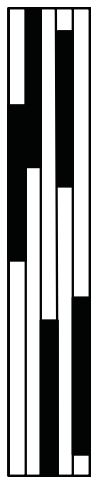

(iii) 

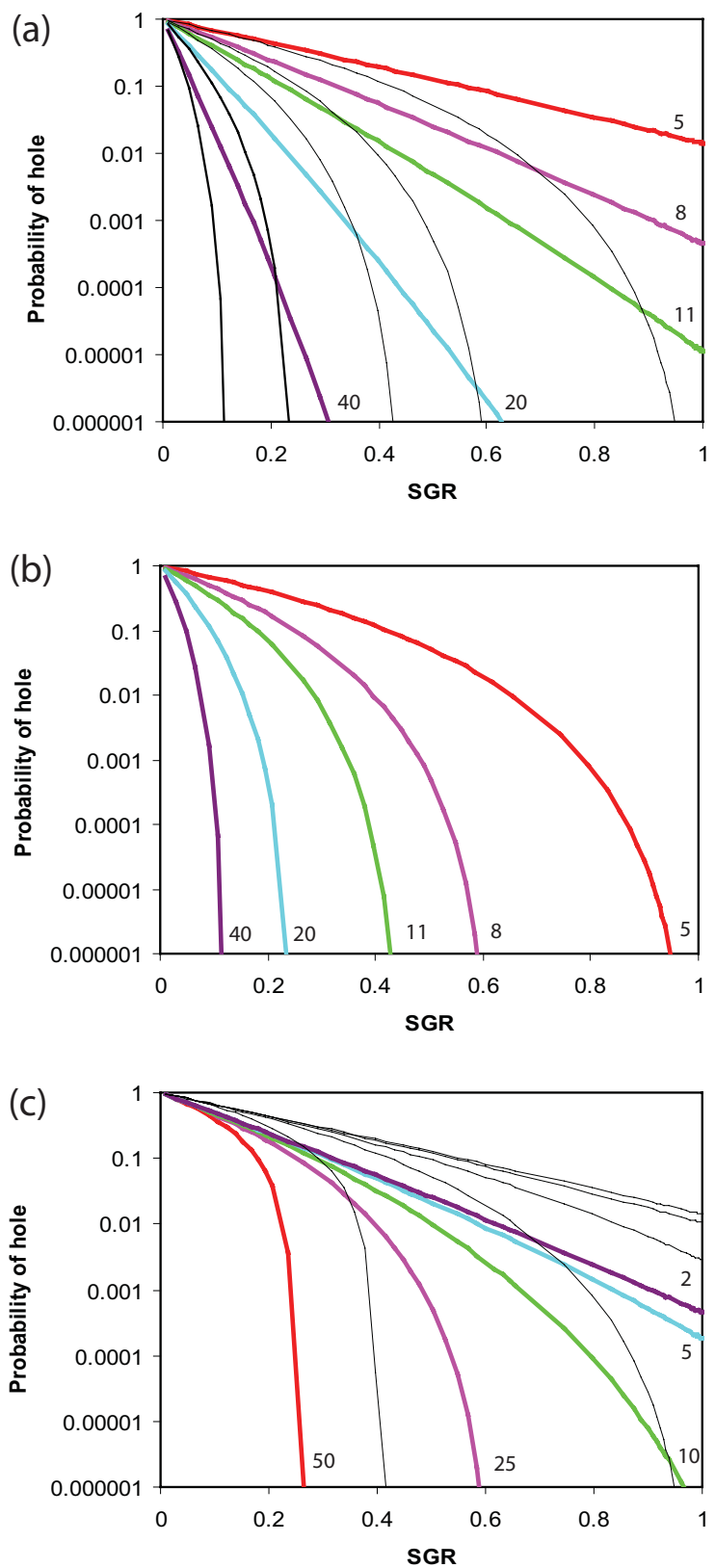

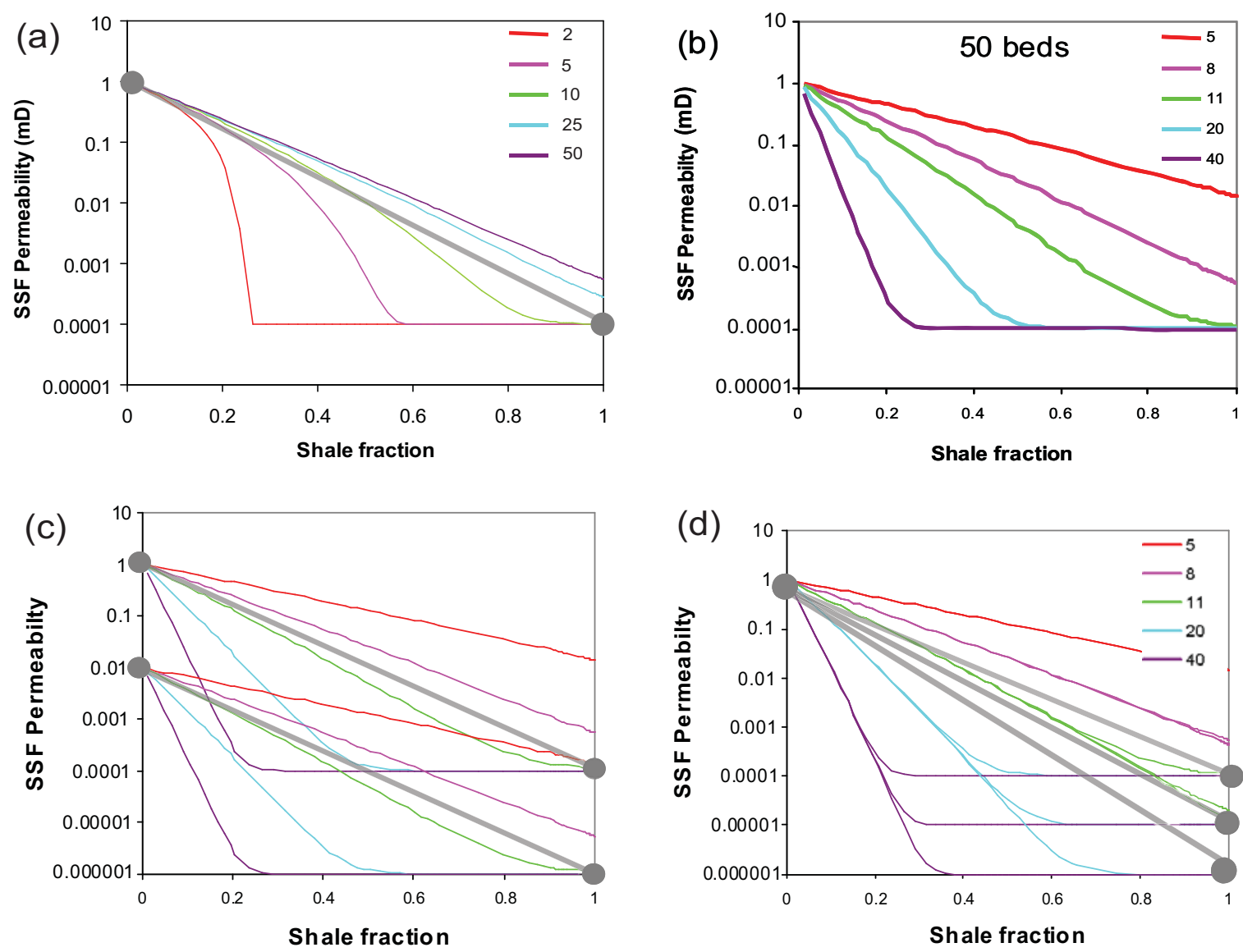

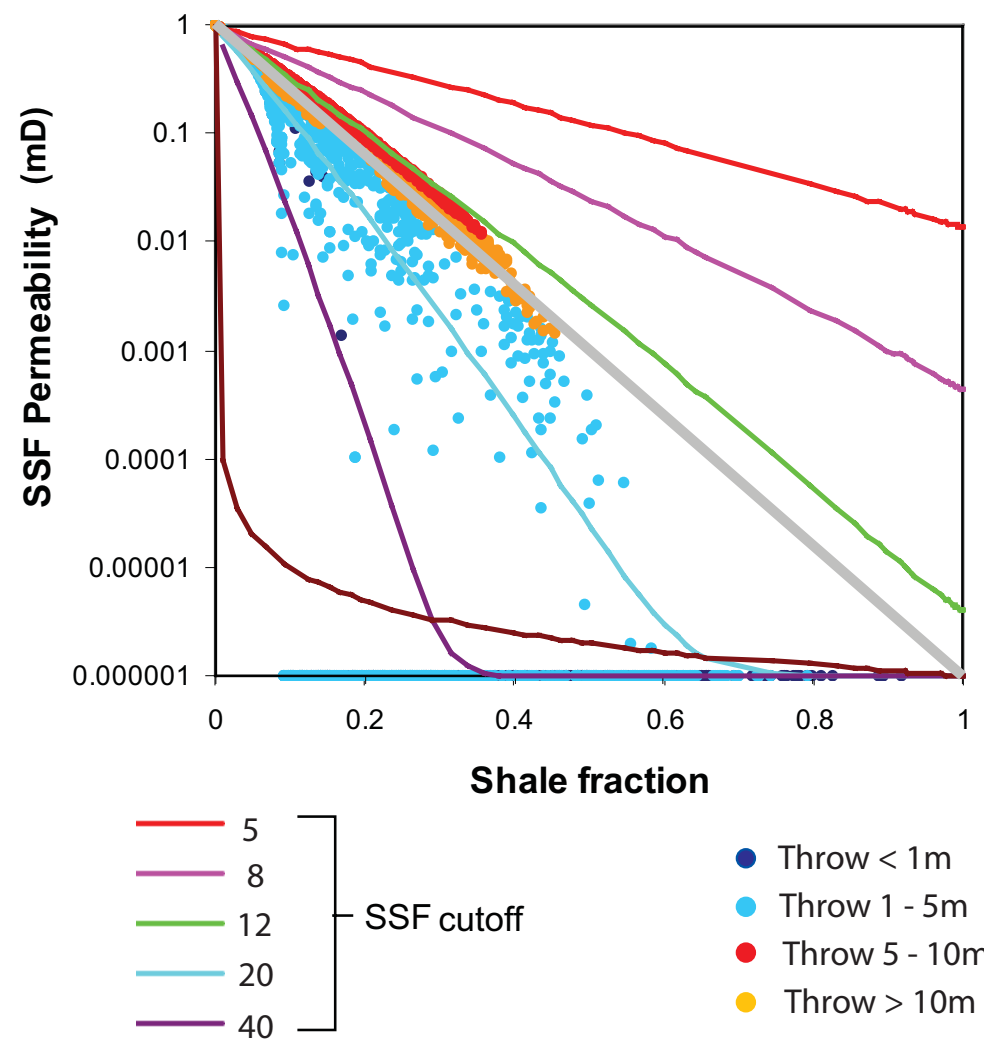

- Throw $<1 \mathrm{~m}$

- Throw 1 - 5m

- Throw $5-10 \mathrm{~m}$

- Throw $>10 \mathrm{~m}$ Harmonic mean 


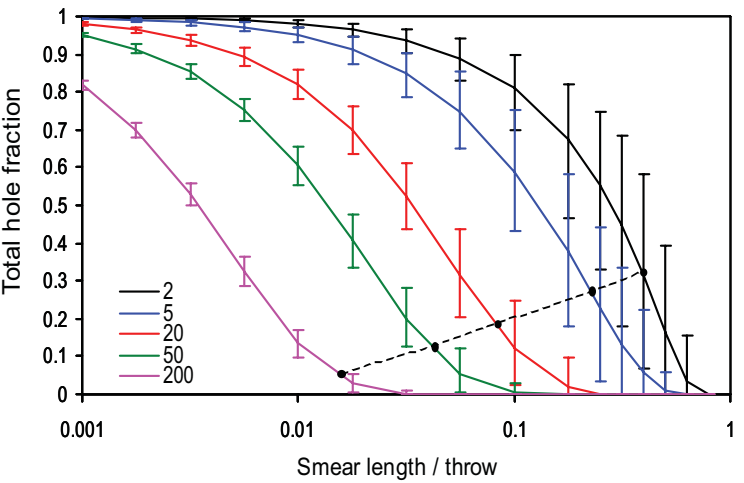



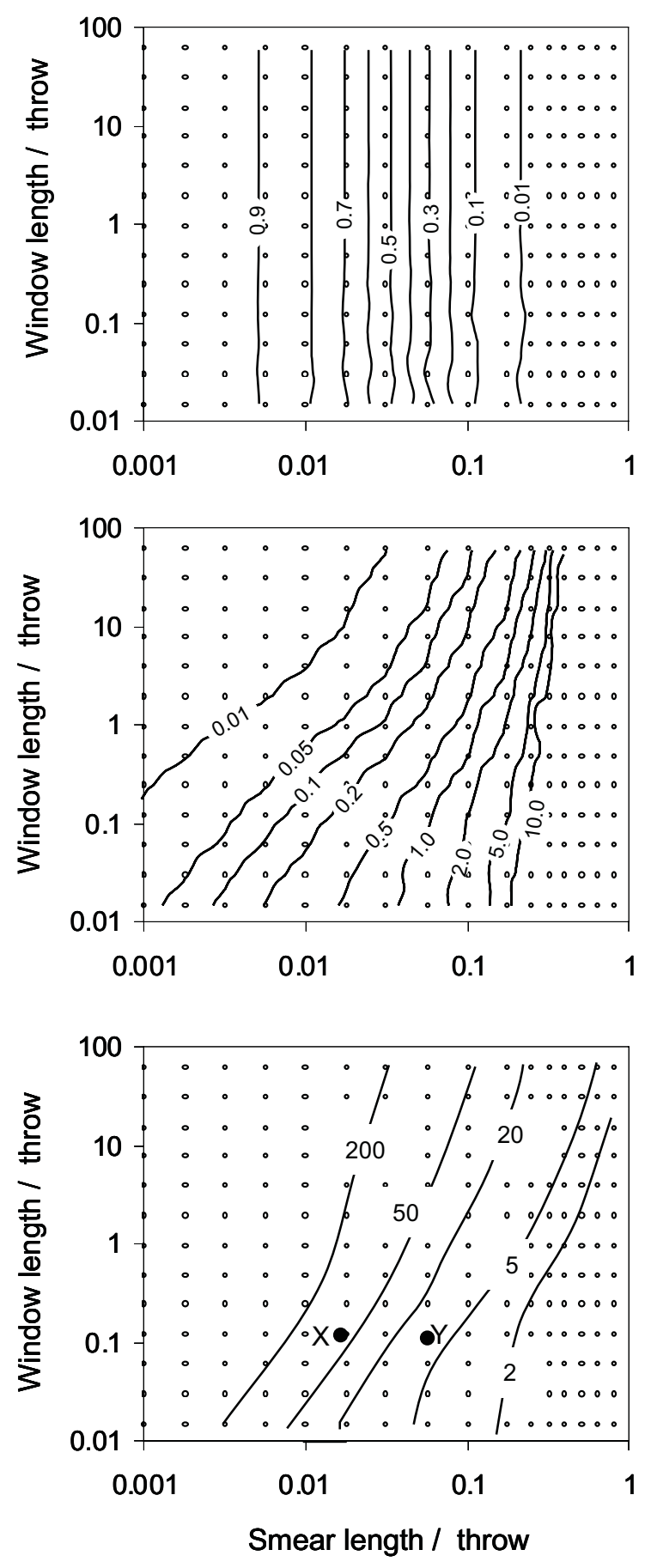